\title{
Impact of structural habitat modifications in coastal temperate systems on fish recruitment: a systematic review
}

\author{
Biljana Macura ${ }^{1 *} \mathbb{D}$, Pär Byström² ${ }^{2}$, Laura Airoldi ${ }^{3}$, Britas Klemens Eriksson ${ }^{4}$, Lars Rudstam ${ }^{5}$ \\ and Josianne G. Støttrup ${ }^{6}$
}

\begin{abstract}
Background: Shallow nearshore marine ecosystems are changing at an increasing rate due to a range of human activities such as urbanisation and commercial development. As a result, an increasing number of structural modifications occur in coastal nursery and spawning habitats of fish. Concomitant to this increase, there have been declines in many coastal fish populations and changes in the composition of fish communities. As requested by Swedish stakeholders, this review aimed to synthesise scientific evidence of the impact on fish recruitment of structural modifications in temperate coastal areas.

Methods: We searched for peer-reviewed and grey literature on such impacts in English, Dutch, Danish, Finnish, German, Swedish and Spanish. Searches were performed in bibliographic databases, specialist websites, bibliographies of review articles. We also contacted stakeholder to find relevant literature. Eligible studies included small-and large-scale field studies in marine systems and large lakes $\left(>10,000 \mathrm{~km}^{2}\right)$ in temperate regions of the Northern and Southern Hemispheres. Included replicated comparisons of fish recruitment between altered and unaltered control areas, comparisons before and after an alteration, or both. Relevant outcomes (response variables) included measures of recruitment defined as abundance of juvenile fish in coastal habitats. All fish species were considered. Articles were screened for eligibility by title, abstract and full text. Eligible studies were critically appraised based on their external and internal validity. From each eligible study of sufficient validity, we extracted information on study design, measured outcomes, exposure, type of comparator, effect modifiers and study findings. Study findings were synthesised narratively.
\end{abstract}

Results: We searched for eligible studies in 15 databases, 24 specialist websites, Google Scholar, and bibliographies of 11 review articles. The review finally included 37 studies that were eligible and of sufficient validity to be considered for final synthesis. Most studies (23 of 37) were from the Northern Hemisphere. Studies varied in design, spatial resolution, target fish species, and type of structural habitat change. This high level of variation did not allow for a quantitative synthesis and prevented us from drawing general conclusions on the impact of structures or structural modifications on fish recruitment. In this review we provide a narrative synthesis of the evidence base and classify eligible studies into six categories (based on type of exposure and comparator). The categories are as follows: the impacts

\footnotetext{
*Correspondence: bmacura@gmail.com; biljana.macura@sei.org; par. bystrom@umu.se

${ }^{1}$ Mistra Council for Evidence-Based Environmental Management (EviEM), Stockholm Environment Institute, Linnégatan 87D, Box 24218, 10451 Stockholm, Sweden

${ }^{2}$ Department of Ecology and Environmental Science, Faculty of Science and Technology, Umeå University, 90187 Umeå, Sweden

Full list of author information is available at the end of the article
} 
on fish recruitment of: (1) artificial structures in coastal areas, (2) structures designed as fish attractors, (3) large scale urban sprawl, (4) 'novel' habitats, (5) habitat loss, and (6) restoration.

Conclusions: This review revealed a very limited evidence base for how structural modifications and marine urban sprawl can affect fish recruitment. Thus, there is a substantial mismatch between stakeholder needs and research evidence. Further, the impact and ecological performance of artificial structures depend both on context and species. Clearly, there is a need for more research on the subject, especially on long-term consequences at larger spatial scales.

Keywords: Artificial structures, Coastal habitat loss, Coastal development, Juvenile fish, Marine urban sprawl, Nursery, Physical habitat change, Spawning ground, Young-of-the-year, YOY

\section{Background}

Anthropogenic activities are degrading and destroying native habitats in coastal ecosystems worldwide $[1,2]$. Shallow sheltered bays and estuaries have been altered by what is generally referred to as "urban sprawl" [3], which is the proliferation of artificial structures and/or the destruction of natural habitats to support maritime traffic, protect low-lying coasts, support aquaculture and fisheries, provide recreational opportunities, or produce energy [4-6]. In addition to persistently modifying coastlines by replacing natural with artificial habitats, infrastructure can also disturb the surrounding environment by changing water flow, light, sediment and nutrient loading, noise, electromagnetic fields and chemical pollution [7] and produce large-scale impacts by alteration of ecological connectivity [8]. Additional disturbance originates from related human activities such as dredging, beach nourishment, boating, and beach tourism. Despite a growing awareness of these impacts [9-11], quantitative estimates of the effects on species distributions and abundances are still scarce $[4,12,13]$.

Shallow coastal and estuarine habitats (including wetlands, seagrass beds, kelp and other canopy forming macroalgae, shellfish and other biogenic reefs) are often spawning and nursery habitats that support the larvae and juveniles of many fish species, including several commercially important species [5, 12, 14-16]. While this nursery role is increasingly studied and defined [16, 17], less effort has been invested to quantify the potential erosion of this critical function as a consequence of often irreversible modifications to nearshore habitats. For example, the historical wetland drainage in coastal Northern Europe resulted in widespread loss of important recruitment areas [18]. Smaller disturbances such as dock construction and boating could also impact shallow coastal nursery habitats [18-20].

In temperate areas, many coastal populations of fish have seen marked declines during the past two decades [21-25]. These declines have been linked to a number of factors including overexploitation [26], environmental change [22], changes in migration and reproductive patterns [27], changes in food webs [28, 29], and destructive fishing practices [30]. However, there is growing awareness that the problem of declining fish abundances is aggravated by factors affecting the survival of earlier life stages of many species $[15,31]$. Several studies have documented a widespread recruitment deficit in species that depend on shallow coastal habitats for reproduction $[18,32]$ and increased mortality during early life stages has been suggested to be the main cause for some declining populations of adult fish [33-35]. For example, continuous declines in density and abundance of coastal top predatory fish like pike (Esox lucius) and Eurasian perch (Perca fluviatilis) have been observed since the mid1990s in parts of the Baltic Sea [35, 36]. At the same time, as much as $40 \%$ of the available reproductive areas were considered degraded or lost by 2005 along parts of this coast [4]. Recent work has also shown that adult densities of the two dominant predatory fish species [zander (Sander lucioperca) and Eurasian perch] were related to the amount of nursery habitat available in a large archipelago area of the Baltic Sea [35]. Moreover, altering the abundance and diversity of large piscivorous fish may invoke community-wide trophic cascades and negative feedback loops that further reinforce the negative impact on piscivore recruitment, with far-reaching consequences for ecosystem functioning, fisheries and human livelihoods [25, 26, 37]. Even so, the impacts of anthropogenic modification of coastlines on fish populations are poorly described and rarely incorporated into scientific advice for fishery management. This is partly due to the difficulties of establishing an empirical link between human impacts, the availability of nursery habitats, and fish recruitment to adult stocks [35, 38, 39]. Therefore, a better understanding of how anthropogenic activities affect coastal habitats and the fish species that depend on them for their recruitment is essential for guiding management actions that aim to preserve, enhance or restore coastal ecosystem services [40-42].

Today, controversies remain over the primary causes of declining coastal fish populations, including the importance of the loss of nursery habitats, the effectiveness of habitat restoration, and the extent to which management can reverse declines in fish stocks [6, 19]. Recently, 
researchers have focused their attention on links between anthropogenic pressures and fish recruitment, and the accumulation of new data (see e.g. [43-47]) suggests that a systematic review on this topic may help resolve some of these controversies. Decision makers and other stakeholders need to know the available evidence for effects of coastal structures and other human-made habitat changes on fish recruitment in order to make appropriate decisions on coastal use and development that consider the function of these coastal areas for fish recruitment.

\section{Topic identification and stakeholder engagement}

As part of the Baltic Sea Action Plan, HELCOM FISHPRO II and contracting parties (http://helcom.fi/helco $\mathrm{m}$-at-work/projects/fish-pro) are compiling data on the status of coastal fish populations in the Baltic Sea (20132018). In 2005, the Swedish National Board of Fisheries presented a survey on recruitment problems in coastal fish populations in the Baltic Sea [15]. This survey suggested that high mortality during larval or early juvenile stages is the likely reason for declining coastal fish populations. It focused on two species (Eurasian perch and pike) and highlighted the inconsistencies in available data and the lack of mechanistic understanding of observed patterns in recruitment. The effects of anthropogenic disturbances on fish communities are a growing national and international concern.

In May 2015, Mistra Council for Evidence-Based Environmental Management (EviEM) organised a meeting with Swedish environmental stakeholders that included representatives of the Swedish Agency for Marine and Water Management, the Swedish University of Agricultural Sciences, county boards and non-governmental organisations. The Swedish stakeholders highlighted the need for a comprehensive summary of how the early life stages of fish may be affected by various human activities in the Baltic Sea. The Helsinki Commission [14] carried out a comprehensive review of the status of coastal fish populations, but the review team could not identify any comprehensive and systematic syntheses of the evidence on how or to what extent anthropogenic activities affect the function of spawning and nursery habitats for fish populations in the Baltic Sea or other similar temperate aquatic environments. Therefore, to overcome the constraints in knowledge, we conducted a systematic review, following the systematic review protocol focusing on the impact of human-made structural modifications on fish recruitment in temperate regions [48]. This article presents the findings of that review.

\section{Objectives of the review}

The primary objective of this review was to collect and synthesise available evidence of impacts of small- and large-scale human-induced structural changes on fish recruitment in nursery and/or spawning grounds in shallow coastal or near-shore aquatic fish habitats in the temperate zone.

Primaryquestion How is fish recruitment affected by anthropogenic structural modifications to habitats in shallow nearshore areas in temperate systems?

\section{Components of the primary question}

Population Shallow coastal or nearshore areas that are nursery and/or spawning habitats of any fish species in temperate regions of both hemispheres. It includes marine and brackish systems, and freshwater lakes larger than $10,000 \mathrm{~km}^{2}$.

Exposure Direct structural modifications of anthropogenic origin in nursery and/or spawning fish habitats. These can be (1) small- and large-scale habitat modifications caused by structures such as ports, jetties, seawalls, canals, nearshore wind farms, tidal energy facilities, (2) coastal protection structures (e.g., breakwaters, groynes, and riprap), beach nourishment or any other shoreline approach against coastal flooding and erosion, (3) underwater structures such as artificial reefs, cables and pipelines, (4) habitat modifications caused by extraction, land reclamation, or habitat enhancement and restoration.

Comparator Spatial (no anthropogenic structural modifications of the habitat) and/or temporal (habitat before the modification).

Outcomes A measure of recruitment of juvenile fish, mainly estimates of abundance of different species. We define recruitment as a measure of abundance of juvenile fish found in shallow nearshore areas. Community composition was not considered. 


\section{Methods}

This systematic review follows the Guidelines and Standards for Evidence Synthesis in Environmental Management by Collaboration of Environmental Evidence [49]. It is designed according to the protocol published in Environmental Evidence in 2016 [48] (but see "Deviations from protocol") and it conforms to ROSES reporting standards (see Additional file 1). Prior to the peer review and publication of the protocol, a draft version was open for public review at the website of the EviEM from mid-December 2015 to mid-January 2016. Comments received from the stakeholders were considered prior to publication of the protocol.

\section{Deviations from protocol}

We have changed the review question to improve clarity. In addition, we have only focused on the changes to juvenile fish abundance as a measure of impact. Studies of changes in community composition were not considered due to our definition of fish recruitment (see "Outcomes" above). More details about deviations from the protocol are explained under specific sections (see "Search strategy" and "Potential effect modifiers and reasons for heterogeneity").

\section{Search strategy \\ Search terms}

The following English language search terms were used:

Population terms: shore*, bay*, coast*, estuar*, lagoon*, lake $^{*}$, intertid ${ }^{*}$, near\$shore, shallow, seagrass ${ }^{*}$, seaweed ${ }^{*}$, wetland $^{*}$, marina*, floodplain*, fiord ${ }^{*}$, mudflat ${ }^{*}$, saltmarsh", eelgrass", "biogenic habitat", "habitat-forming specie"*", "kelp forest"*, "mussel bed"”, "oyster bed", "Sabellaria bed"*", "sand bank", "shellfish habitat", littoral, marsh", macrophyt", "maerl bed", "habitat-engineer* species", "canopy-forming alga*", "fucoid alga*"

Exposure terms: "artificial reef*", "artificial structure*", armo\$r*, "beam trawling", cable*, dock", drain*, dredg*, "habitat change", "habitat degradation", "habitat loss", "habitat restoration*", pier*, pipe\$, port\$, reclamation*, "wind farm"*", "wind turbine" genic pressure", man\$made, "hydrological connectivit", "habitat connectivit"", seawall", "coastal defen*", breakwater", buoy", gabion*, groyne*, jett", "landing stage", "aggregate extraction", revetment", "hard engineering", mooring", drill", "flood gate ${ }^{*}$, floodgate*, dike*, "ship channel*", "shipping lane*", "tidal energ"," "wave energ*", "habitat complexit", "habitat enhancement", "habitat fragmentation", "beach nourishment"

Outcome terms: "age $\$ 0$ ", fish", "fish juvenile*", "fish larva*", "fish nurser*", "fish recruit"” "YOY",
"Young\$of\$year", "Young\$of the\$year", “0\$group", "fish spawn"”, "fish reproduct", “CPUE”, “0 + fish", "fish abundance $*$ ", "fish densit", "fish diversit*", "fish rich"

The search terms within each of the three categories (population, exposure and outcome) were combined using the Boolean operator 'OR'. Wild cards (for single characters $(\$)$ or any group of characters $\left({ }^{*}\right)$ ) were also used. We combined the three categories into a search string using the Boolean operator 'AND'.

The review team tested the search string in Web of Science against a list of 20 relevant articles. The final set of search terms was the result of numerous iterative searches in Web of Science that allowed for further refinement of the search string and aimed to increase the overall comprehensiveness of the search. The full record of these iterations is in Additional file 2. The final search string located all 20 test articles.

The search string was modified depending on the functionality of different databases, specialist websites and search engines. In some cases, only a few key search terms were used (e.g. "fish recruitment" or "fish habitat change"). In addition to English, searches were made for studies in Dutch, Danish, Finnish, German, Swedish and Spanish with translated search terms. Details of all these searches including the adaptations of searches to specific databases, websites and search engines are in Additional file 2.

Recorded references were imported into an EndNote library and EPPI-Reviewer (online systematic review software). All duplicates were removed, and their numbers were recorded.

\section{Publication databases}

The search included the following online databases:

1. Academic Search Premier (ASP)

2. Aquatic Sciences and Fisheries Abstracts (ASFA)

3. Biological Abstracts

4. COPAC

5. CAB Abstracts

6. DART-Europe E thesis

7. Directory of Open-Access Journals

8. EthOS (British Library)

9. GeoBase

10. ProQuest Dissertations and Theses (Index to Theses Online)

11. JSTOR

12. PiCarta

13. Scopus

14. SwePub

15. Web of Science Core Collection 
The searches in these databases were performed in English only. The access was provided by Stockholm University library to all databases, with exception to $C A B$ Abstracts (Cornell University) and Picarta (The University of Groningen).

The search was performed in two phases: February 2016 and May-June 2017. During February 2016, we searched all 15 publication databases (see Additional file 2) and this search was updated in May 2017 by searching in Web of Science Core Collection, ASP, ASFA, GeoBase and SwePub.

\section{Search engines}

An internet search was performed in May and June 2017 using Google Scholar (http://www.scholar.google.com) and search terms in English, Dutch, Danish, Finnish, German, Swedish and Spanish. We examined all relevant hits, not only the first 200 hits as stated in the protocol. These hits were downloaded (first, into a Mendeley database and then uploaded to EPPI software). We did not use google.com (as described in the protocol) due to the high number of irrelevant search results when using that search engine.

\section{Specialist websites}

Websites of the specialist organisations listed below were searched in May and June 2017 for links or references to relevant articles and data, including grey literature. The searches were performed mainly in English, and where possible, in Danish, Finnish and Swedish.

1. Baltic Marine Environment Protection Commission (http://www.helcom.fi).

2. Centre for Environment, Fisheries and Aquaculture Science (http://www.cefas.co.uk).

3. Danish Centre for Environment and Energy (http:// www.dce.au.dk).

4. European Commission Joint Research Centre (http://www.ec.europa.eu/dgs/jrc).

5. European Environment Agency (http://www.eea. europa.eu).

6. European Fisheries and Aquaculture Research Organisation (http://www.efaro.eu/).

7. FAO Fisheries and Aquaculture Department (http://www.fao.org/fishery/en).

8. Natural Resources Institute Finland (http://www. luke.fi).

9. Finland's environmental administration (http:// www.environment.fi).

10. Fisheries and Oceans Canada (http://www.dfompo.gc.ca/index-eng.htm).

11. Government of Canada, Federal Science Library, DFO collection (formerly known as WAVES data- base) (http://fsl-bsf.summon.serialssolutions.com/ en/advanced).

12. Great Lakes Fishery Commission (http://www.glfc. $\operatorname{org} /)$.

13. Greenpeace (http://www.greenpeace.org/).

14. International Council for the Exploration of the Sea (http://www.ices.dk).

15. National Marine Fisheries Service (http://www. nmfs.noaa.gov/).

16. The Nature Conservancy (http://www.nature.org/).

17. The Royal Netherlands Institute of Sea Research (http://www.nioz.nl/home_en).

18. Senckenberg (http://www.senckenberg.de/).

19. Swedish Agency for Marine and Water Management (http://www.havochvatten.se).

20. Swedish Environment Protection Agency (http:// www.naturvardsverket.se).

21. Swedish Environmental Research Institute (http:// www.ivl.se).

22. United Nations Environment Programme (http:// www.unep.org).

23. United States Environmental Protection Agency (http://www.epa.gov).

24. World Wide Fund For Nature WWF (http://wwf. $\operatorname{org} /)$.

\section{Other literature searches}

To further ensure the completeness of our search, we checked the bibliographies of 11 literature reviews (MayJune 2017), and all relevant references that were not captured by previous searches were recorded and extracted (Additional file 2). Attempts to obtain unpublished data were made through calls for evidence using ResearchGate.net (May 2016, no additional studies found), as well as contacting stakeholders and experts in the field for suggestions of relevant studies (yielded one additional article).

\section{Article screening and study eligibility criteria Article screening}

Articles were evaluated for relevance based on the eligibility criteria at three levels: title, abstract and full-text. Articles were first evaluated for eligibility based on their titles. To control for reviewer consistency, at least two reviewers independently assessed a subset of 100 titles. The level of agreement between reviewers was calculated by a kappa statistic. Discrepancies were discussed in cases where there was an indication of inconsistency between reviewers (kappa index $(\kappa)<0.6$ ), the eligibility criteria were clarified. The screening consistency tests were repeated until the $\kappa$ reached 0.6 or more. The rest of the articles were then evaluated by one of the reviewers 
for eligibility based on their titles. Next, each article was judged for eligibility based on its abstract. This procedure was also evaluated for screening consistency as described above on a subset of 100 abstracts. The rest of the articles were then evaluated for eligibility by one reviewer. Each article found to be potentially relevant based on its abstract was judged for eligibility by screening the full text. Screening consistency was also checked at this stage, but on a smaller subset of 25 full texts, and all disagreements were discussed. The full-text screening on remaining papers was then conducted by one reviewer. At each screening stage, reviewers were asked to include rather than exclude studies when uncertain. Studies or datasets found from sources other than database searches were entered at one of the two latter stages of this screening process.

\section{Study eligibility criteria}

The following eligibility criteria were applied (as described in the protocol [48]):

Relevant subjects Any coastal nursery and/or spawning habitats for fish species. These habitats had to be located in temperate zones of both hemispheres, in marine and brackish systems or in lakes that are larger than $10,000 \mathrm{~km}^{2}$. The temperate coastal region was defined using a map of the world's marine ecoregions [50]. However, during the review process we extended our scope to all studies from non-tropical regions, including the following realms: South Ocean, Arctic, Temperate Northern Atlantic, Temperate Northern Pacific, Temperate South America, Temperate Southern Africa, Temperate Australasia. For inland freshwater systems, we used the KöppenGeiger climate classification [51] and limited studies to warm temperate (including: $\mathrm{Cfa}, \mathrm{Cfb}, \mathrm{Cfc}, \mathrm{Csa}, \mathrm{Csb}, \mathrm{Csc}$, Cwa, Cwb, Cwc) and snow climate zones (including: Dfa, Dfb, Dfc, Dfd, Dsa, Dsb, Dsc, Dsd, Dwa, Dwb, Dwc, Dwd) in both hemispheres. We applied the definition of 'coastal waters' from the European Water Framework Directive (L $327 / 6$, Art. 2) [52] and focused on the marine area located up to one nautical mile from the coast.

Relevant types of exposures These can be (but are not restricted to) small- and large-scale human-made structures in nearshore areas: ports, docks, jetties, canals, coastal protection structures (e.g. groynes, sea walls, revetments, rock armouring, gabions, and breakwaters); other structures such as nearshore wind farms or oil platforms, and underwater nearshore structures such as artificial reefs, cables and pipelines. Small- and largescale structural changes of relevant aquatic habitats due to dredging, aggregate extraction, beach nourishment, land reclamation or habitat restoration activities were also included. Studies on barriers affecting adult fish migration and connectivity between adjacent freshwater spawning habitats and the nearshore marine or large lake nursery grounds were included for species such as percidae, esocidae and cyprinidae but not for species normally migrating longer distances upstream (salmonidae, catostomidae, clupeidae). We excluded studies that evaluate effects of non-structural changes of the habitat, such as change of temperature or chemistry of the aquatic system (including effects of pollution, toxicity, eutrophication or oxygen depletion), conservation policy interventions (e.g. the effects of marine protected areas), or the effects of climate change and rising sea levels on the fish stocks. Similarly, we did not include studies that evaluate effects of water abstractions (for aquaculture or similar purposes).

Relevant types of comparator All studies that compare relevant outcomes between undisturbed and disturbed areas (control/impact (CI) design) and/or compare relevant outcomes before and after an exposure (before/after (BA) design). Eligible studies present data from a single post-disturbance sampling occasion, or repeated data collection over several years.

Relevant types of outcome Measures of recruitment of juvenile fish, primarily estimates of abundance. All fish species and species groups were considered in this review.

Relevant types of study Any type of field study in coastal habitats. Theoretical, modelling and laboratory-based studies were excluded.

Language Full texts written in English, Dutch, Danish, Finnish, German, Swedish and Spanish.

\section{Study validity assessment}

Eligible studies were subject to a critical appraisal. A study could be published in two articles, or one article could contain multiple studies. We defined individual study' as any study which had a defined set of methods, defined and unique combination of treatments and study locations.

The appraisal was conducted in a similar way to other reviews by EviEM (see [53]). The team assessed study validity and categorised relevant studies as having high, medium or low validity. Validity criteria included both susceptibility to bias (internal validity) and relevance of the study for our review question (external validity). Studies with high, medium and unclear validity were included in the narrative synthesis, whereas studies with low validity (i.e. high susceptibility to bias) were excluded.

The validity of a study was appraised by two reviewers. A small subset of the studies (10\%) was appraised by 
the entire review team at the beginning of the appraisal to check for appraisal consistency, and all disagreements were discussed, and the criteria further refined. Final decisions regarding doubtful cases were taken by the whole review team.

A study was excluded from the narrative synthesis due to low validity if any of the following factors applied:

- No replication (i.e. less than two independent experimental/observational units).

- Exposure and comparator sites not matched (e.g. different habitat or ecosystem type).

- Severely confounding factors present (e.g. additional treatments carried out at the exposure sites but not at the comparator sites, or only before/only after the modification; different sampling method between exposure and control sites).

- Juvenile data not separable from adult data.

Some studies did not report sufficient details to judge their validity; those studies were categorised as having unclear validity. Specifically, a study was categorised to have unclear validity if any of the following factors applied:

- Poor methodological description (e.g. absence of key information on study design, or sampling procedure).

- Exposure difficult to interpret (e.g. unclear if the exposure is of anthropogenic origin or if control areas are unaffected by human activities).

A study not assessed to have low or unclear validity was considered to have medium validity if any of the following factors applied:

- BA study design (multiple temporal observations of a single unit in one study context) (not CI or BACI).

- Replication of sample less than ideal, for example if there were repeated measures and lack of independence between observational units (pseudoreplication), uncertain or uneven sample areas, or unbalanced sampling design.

If none of the above factors applied, the study was considered to have high validity. Information regarding validity appraisal for studies judged to be of high and medium validity is located in Additional file 3 (columns $\mathrm{K}$ and $\mathrm{L}$ ). List of studies excluded from the narrative synthesis due to low validity with reasons for exclusion is in Additional file 4 .

\section{Data extraction strategy}

We extracted data and metadata on study characteristics, description of exposure, outcomes, type of comparator, effect modifiers and study findings.

In cases where relevant data were published and available at a sufficient level of detail, but the authors did not conduct statistical analyses on reported data of interest, outcome means and measures of variation (standard deviation, standard error or confidence intervals) were extracted from tables manually and from graphs using WebPlotDigitiser (https://automeris.io/WebPlotDigitize $\mathrm{r} /$ ). Where data presented in graphs were difficult to read, we requested data from the authors. The extracted data records were then used for additional statistical analyses to derive estimates of the impact (t-tests). For studies with repeated temporal measurements and sufficient data we ran statistical models on the reported outcomes to account for differences in time scales and time-dependent responses of juvenile abundance. Within the models, we considered the effects of the treatment, time, and their interaction on abundance, while controlling for the effect of replication. Selected models included: (1) a generalized linear model that incorporated replicates as an explanatory variable, (2) a linear mixed effects model with replicates added as a random effect, and (3) a generalized additive model with smoothing splines incorporated for time and replicates added as a random effect. We measured how well models performed using the Akaike information criterion [54]. All analyses were ran in R (version 3.5.1) [55]. Linear mixed effects models were conducted using the 'lme4' package [56], and the generalized additive models were conducted using the 'gam' function in package 'mgcv' [57]. To obtain estimates of the impact, we ran analyses on the whole available dataset in five studies [58-61], while in three studies we ran analysis on part of the data [62-64]. The extracted data records along with details and results of tests performed are available in Additional file 5.

In some cases [18, 65-69], authors did not perform statistical tests to derive estimates of the impact, and relevant data were not reported in sufficient detail to be analysed by the review team. In such circumstances, no findings were obtained.

To assure that the extraction of data and metadata was repeatable, two reviewers independently extracted data and metadata from a subset of the studies. All disagreements among reviewers were discussed and the coding scheme clarified. All entries were then extracted by one reviewer and cross-checked by another reviewer. 
Potential effect modifiers and reasons for heterogeneity Effect modifiers considered were:

1. Type and characteristics of the exposure.

2. Type of comparator: spatial and/or temporal.

3. Experimental design: observational, experimental; duration of the study/experiment, sampling depth.

4. Structure of the habitat: type of biogenic community (e.g. seaweeds, seagrasses, marshes, shellfish reefs, benthic communities), type of study system (marine, brackish, lacustrine).

5. Coordinates of study sites (latitude and longitude) and climate zone.

According to the availability of information reported in the included studies we updated and simplified the list of effect modifiers initially published in the protocol [48]. The list was further refined based on discussions within the review team.

Where coordinates of study sites were not available from the included articles, we retrieved them from Google Earth. Based on locations of study sites, we retrieved and extracted matching climate data (using $\mathrm{R}$ package rgdal [70]). Studies located in marine coastal ecosystems were classified using the marine ecoregions of the world [50]. Large inland aquatic systems were classified with the Köppen-Geiger climate classification.

\section{Data synthesis and presentation}

We synthesized the studies included in this review in narrative form. The narrative table is available in Additional file 3 and it consists of the following details:

- Study ID

- Full reference

- Language of article

- Study category

- Study validity

- Reasons for medium/unclear validity

- Location of study site(s)

- Characteristics of study site(s) (climate, study system, habitat type)

- Exposure description

- Study design (BA/CI/BACI), experimental design (experimental/observational), study duration and sampling frequency

- Study description and summary of study findings

- Fish species or group of species studied

For some studies, we were not able to extract juvenile fish response data. We kept these studies in the narrative synthesis and flagged them in the Additional file 3 (see columns AE, AF and AG).
Included studies were dissimilar in terms of exposure studied, having disparate study designs and differed substantially in study duration and spatial resolution. Moreover, reported outcomes (juvenile abundances and densities) were heterogeneous in terms of studied species, as well as in terms of data reporting. These differences, along with the small number of included studies with diverse ecological contexts, made a quantitative synthesis of these studies to be of very limited value (if any), and potentially misleading. Therefore, we did not conduct a quantitative synthesis [71].

\section{Results}

Literature search, retrieval, screening and appraisal

All the literature sources used in the review and the number of studies included at different stages of the review are in Fig. 1. A list of unobtainable articles is available in Additional file 6, and a list of articles excluded at full text screening stage, together with reasons for exclusion, is available in Additional file 7.

Twenty-five studies (from 20 articles) were excluded from the narrative synthesis due to low validity: two studies had flaws in the design, six were not replicated, six had no relevant comparator, and in 11 studies data on juvenile or young-of-the-year (YOY) fish outcomes were not available or separable from adult data. A list of studies excluded from the narrative synthesis based on validity assessment is provided in Additional file 4 together with the reasons for exclusion.

This review narratively synthesized 37 studies (originating from 37 articles) and Additional file 3 includes a narrative table describing all included studies in detail. In most cases there was only one study per article, but the article by Laurel and colleagues included two studies [73], and two articles by Reed and colleagues [74, 75] were a single study.

\section{Characteristics of studies included in narrative synthesis}

Publication year of included articles in relation to type of article is shown in Fig. 2. All the included articles were in English, the majority of which were academic peerreviewed journal articles (33). The exceptions were one article from a conference proceedings [65], two reports $[75,76]$ and one dissertation [77].

Across the 37 studies, the most commonly studied country location was the US, followed by Canada (Table 1). A majority of the studies (35) were in coastal marine or brackish systems (including estuaries, coastal wetlands and marshes); three of which were from the Baltic Sea $[18,78,79]$. Two studies were from the freshwater lentic systems of Laurentian Great Lakes $[58,77]$.

Based on the geospatial information extracted from the studies, we built an 'evidence atlas' to show the 
ROSES Flow Diagram. Version 1.0
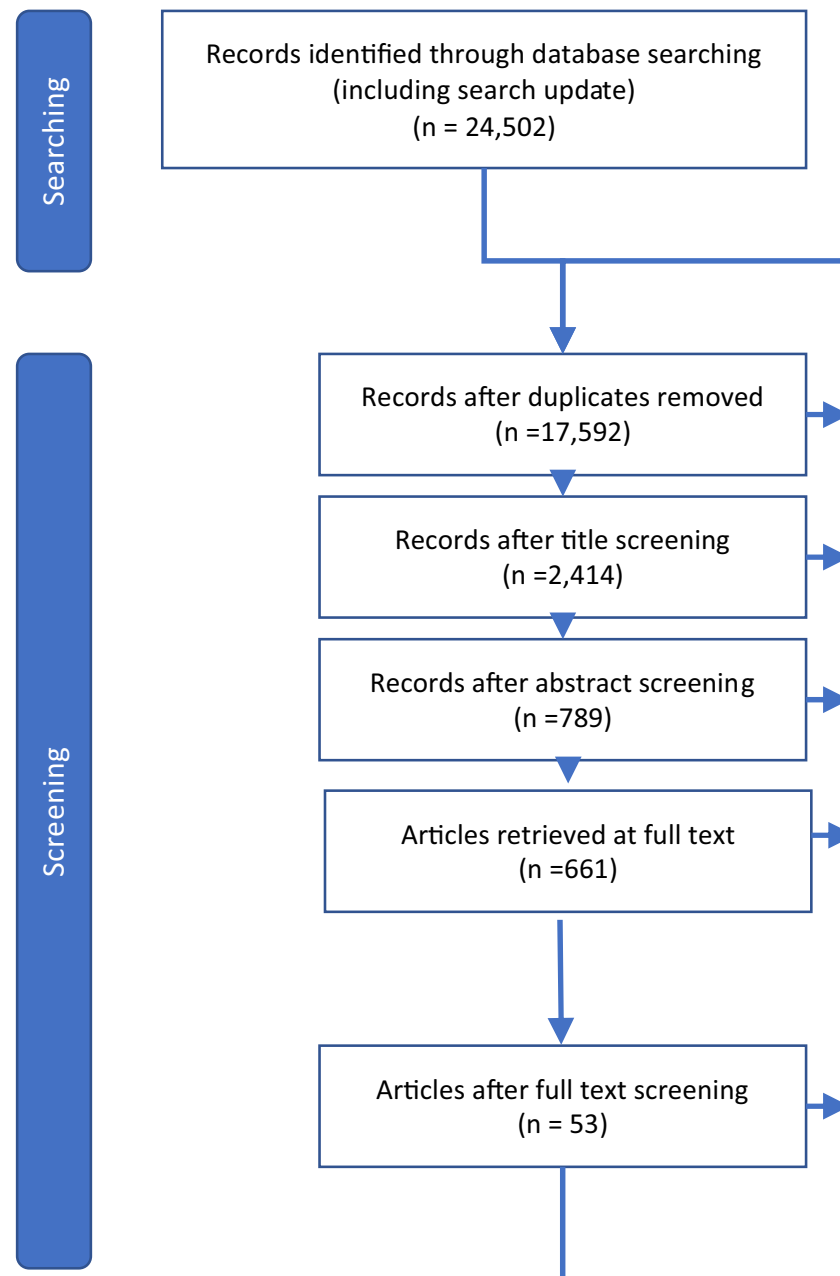
( $n=661$ )
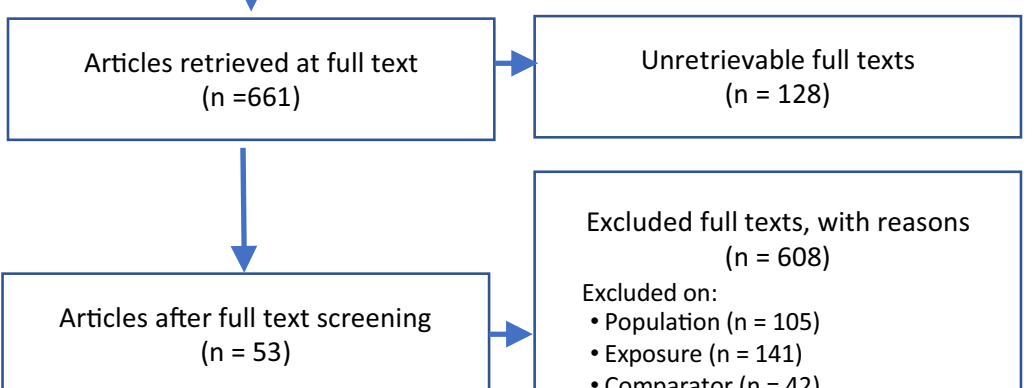

Excluded full texts, with reasons

$$
(n=608)
$$

Excluded on:

- Population $(n=105)$

- Exposure $(n=141)$

- Comparator $(n=42)$

- Outcome $(n=178)$

- Study type $(n=95)$

- Language $(n=10)$

- Climate zone $(n=33)$

- Redundant ( $n=4)$

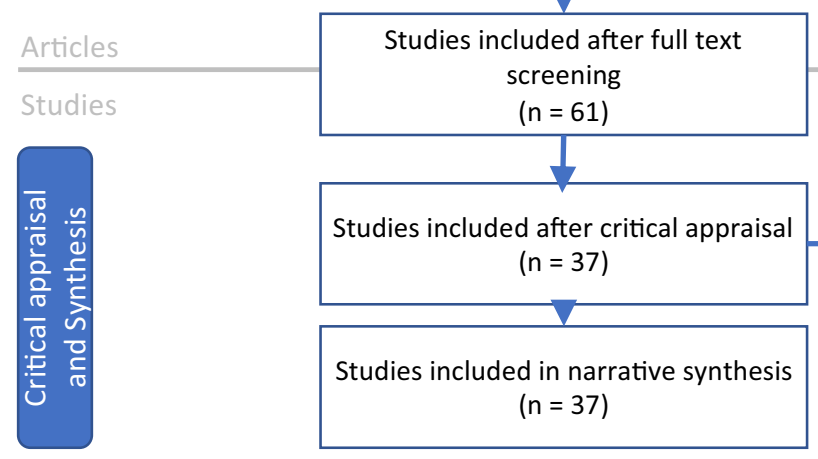

Excluded studies $(n=25)$ :

- Design flaws ( $n=2)$

- No replication $(n=6)$

- No comparator $(n=6)$

- No outcome ( $n=11)$

Fig. 1 ROSES flow diagram [72] showing literature sources and inclusion/exclusion process

geographical distribution of studies across climate zones, and it is available here: http://bit.ly/EvidenceAtlas_Recru itment. Figure 3 shows a snapshot of the evidence atlas.
The majority of coastal marine and brackish studies belonged to the Temperate Northern Atlantic (15 out of 35 studies) and Temperate Northern Pacific (13) realms of Marine Ecoregions of the World [50]. Six 


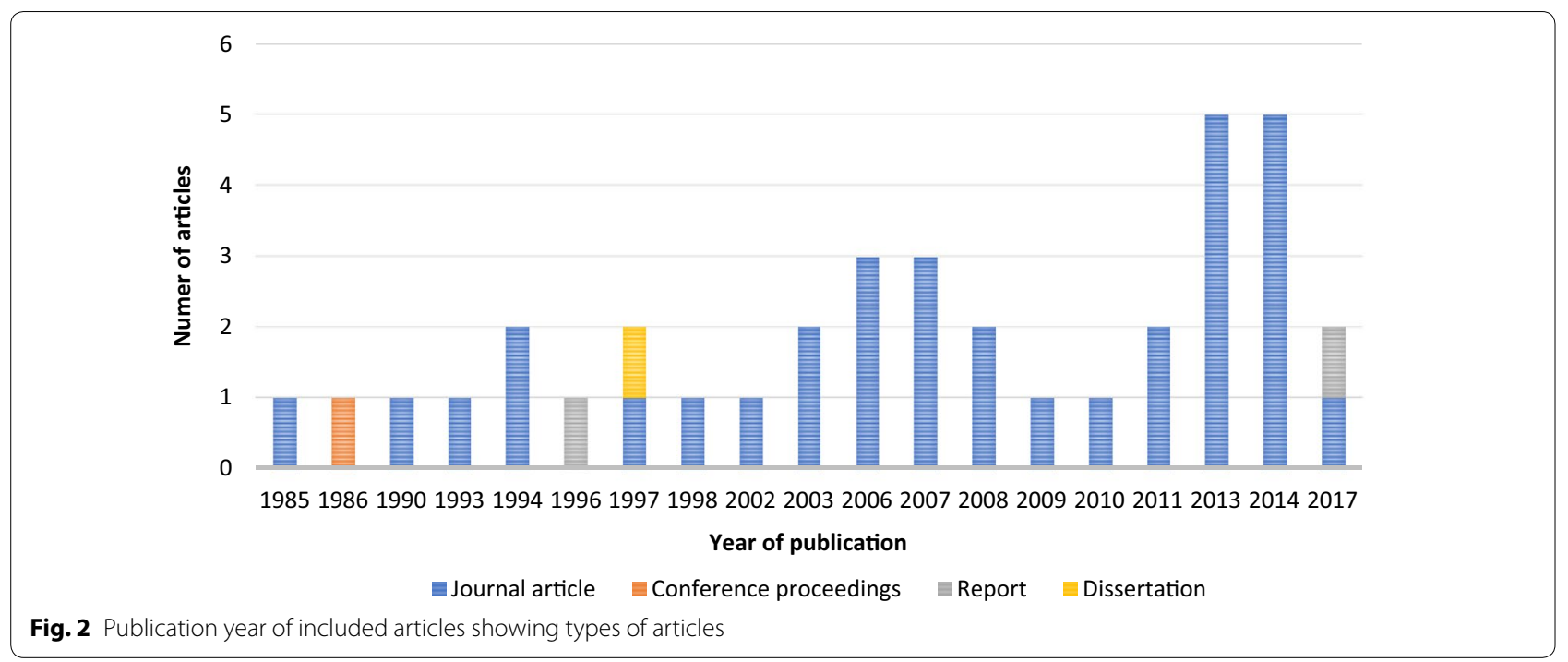

Table 1 Number of studies per country and continent

\begin{tabular}{llc}
\hline Continent & Country & $\begin{array}{l}\text { Number } \\
\text { of studies }\end{array}$ \\
\hline Asia & China & 1 \\
Australasia & Australia & 2 \\
Europe & Finland & 1 \\
Europe & France & 3 \\
Europe & Germany & 1 \\
Europe & Italy & 2 \\
Europe & Sweden & 3 \\
North America & Canada & 5 \\
North America & Mexico & 1 \\
North America & USA & 17 \\
South America & Brazil & 1 \\
South America & Chile & 1 \\
\hline
\end{tabular}

In one study, study sites were located both in Sweden and Finland

studies belonged to the Arctic (3), the Temperate South America (2) and the Temperate Australasia (2). Both studies from the freshwater systems belonged to 'snow fully humid climate zone with warm summers' (Dfb) of Köppen-Geiger climate classification [51].

Most of the studies were judged to be of high validity (24), 12 studies had medium validity and 1 unclear validity. Out of 12 studies with medium validity, six were pseudoreplicated, four had no properly matched comparator and impact sites and three had only temporal comparator (i.e. BA studies).

There were 22 experimental and 15 observational studies. The majority of the studies had CI design, with only 3 BA studies [18, 80, 81] and 3 BACI studies [73, 82]. One study had both BA and CI design (depending on the reported outcome) [69]. More than half of the studies
(21) collected data for more than 12 months and only five studies lasted four or more years [73-75, 78, 80].

In six studies no specific findings on response of fish recruitment could be obtained, because authors collected juvenile or YOY data from reference and exposure sites but did not statistically test differences to derive magnitude or to understand the direction of the impact, nor did they report data in sufficient detail for us to run statistical analyses [18, 65-69] (also see Table 2).

\section{Narrative synthesis including study validity assessment}

This review included studies that measured effects of habitat disturbances, structural modifications, introduced structures to enhance recruitment, or interventions to restore habitats. According to the type of studied impact and the comparator, we classified the studies in six categories that we describe below (see Table 2 and Fig. 3).

The design and outcomes of the studies within different categories varied substantially; therefore, we were unable to provide any overall summary of the effect of specific structures or modifications. Instead, we refer to individual study findings and provide description of their outcomes (details available in Additional file 3). This approach may encourage vote counting, that is, tallying up studies that show significant positive effects, non-significant effects and significant negative effects to determine the direction of the overall effect [83]. However, that approach ignores the magnitude of the effect, the uncertainty around the effect estimate, and variability in methodological rigour of tallied studies, 


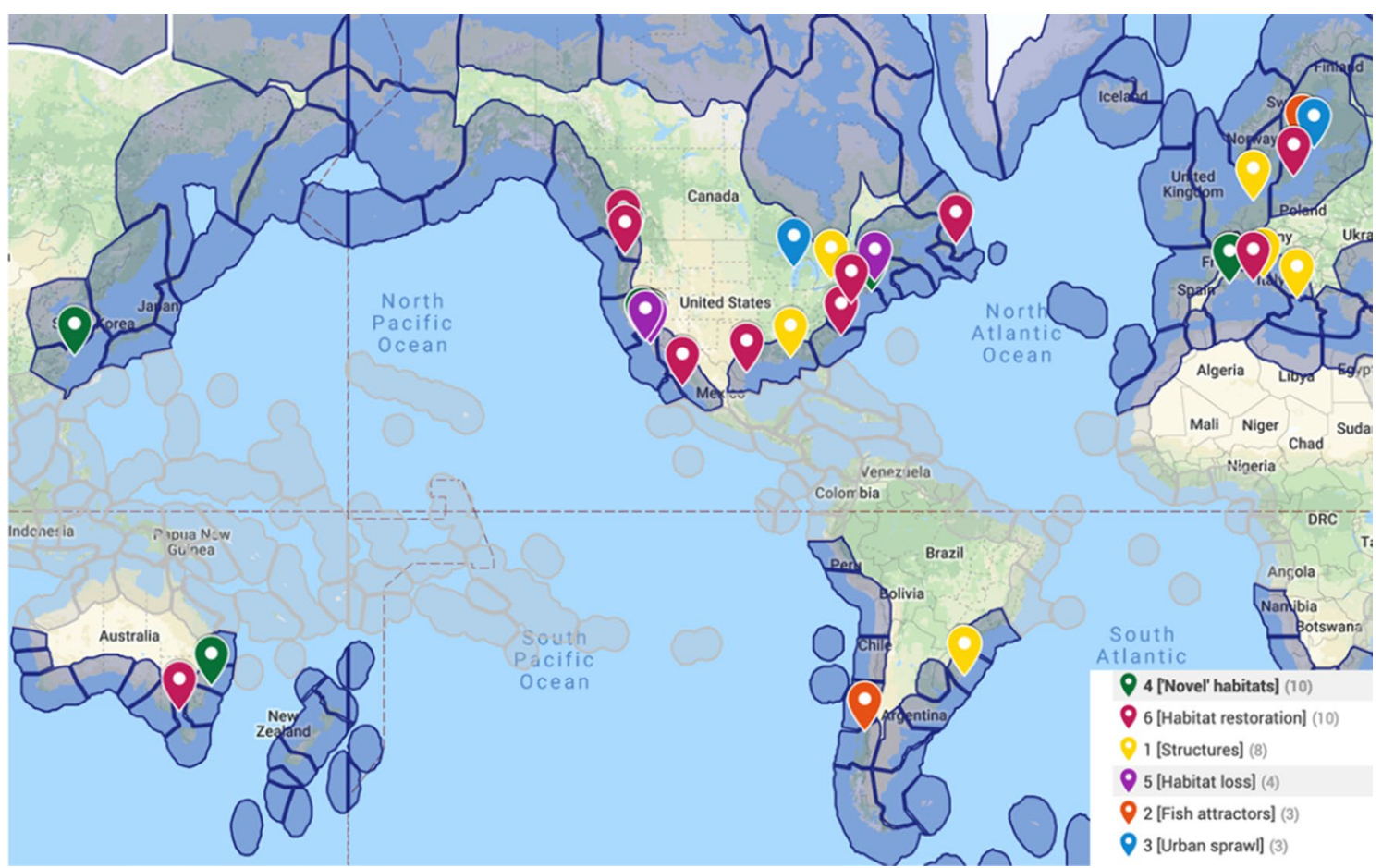

Fig. 3 Geographical distribution of the included studies within relevant marine ecoregions of the world (shaded areas). Studies that belong to the same study category are marked with the same colour (see legend)

and should never be used without effect size calculations (see [84]).

\section{Human-made structures: effects through local modification, degradation or loss of native nursery habitat}

This category included studies that examined, for example, fish recruitment in an area with constructed breakwaters compared to fish recruitment in the area before the construction was completed (BA design), and/or compared to fish recruitment in surrounding unaffected areas (CI design) characterised by a prevalence of native habitat types and communities similar to those that were impacted by the development. More generic 'urban sprawl' impact was covered by the subsequent category 3 .

This category included eight studies $[60,64,69,77,80$, 85-87]. Most of the studies were located in the Northern hemisphere (seven), and in the USA (three studies, $[80,85,86])$, followed by Italy (two, $[64,87])$, Germany (one, [69]), and Canada (one, [77]). In the Southern hemisphere there was only one study from Brazil [60]. The majority of studies were in marine coastal ecosystems, with exception of one study in Lake Ontario [77]. Studies varied in internal and external validity: five were judged to have high validity $[60,64,69,85,86]$ and three were assigned medium validity [77, 80, 87]. Medium validity was assigned due to design issues such as a lack of independence between experimental/observational units $[77,87]$ and lack of spatial control [80]. There were no studies with unclear validity.

Six of the studies were observational and two were experimental $[69,86]$. All studies were designed as CI, except one with a BA design [80]. Additionally, one study [69] showed data from both CI and BA comparisons (subject to a specific outcome). In three studies, sampling lasted from two to four consecutive months $[64,77,85]$, others sampled from one to 1.5 years $[60,87]$ or several consecutive years $[69,80,86]$. Exposures included: areas with coastal protection structures such as breakwaters built either with rocks, boulders or concrete tetrapods $[64,69]$ or with oyster shells [86]; areas subjected to a breakwater rebuilding event [80]; ripraps [77, 85]; overwater structures [85] and rocky jetties [60]; and concrete walls and other anthropogenic debris [87]. Comparators were similar unaffected areas (either bottom sediment, cobble beaches or rocky coastlines, depending on the prevailing characteristics of the exposure) except for Pondella and Stephens [80] where the comparator was the same area before the rebuilding event. Reported outcomes were abundance (or density) of individual juveniles (sometimes limited to YOY fish) of a species, or juveniles of groups of species. 


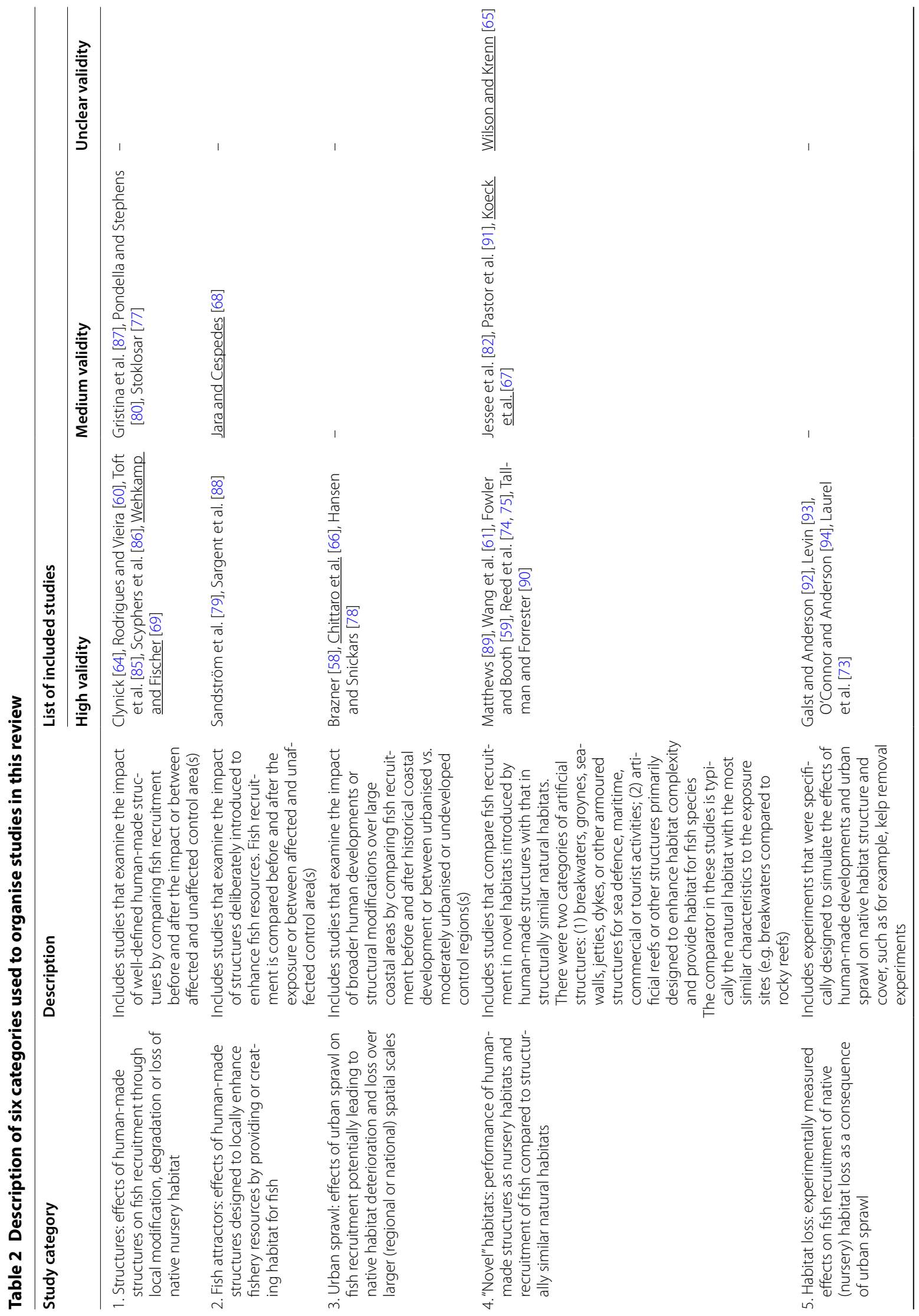




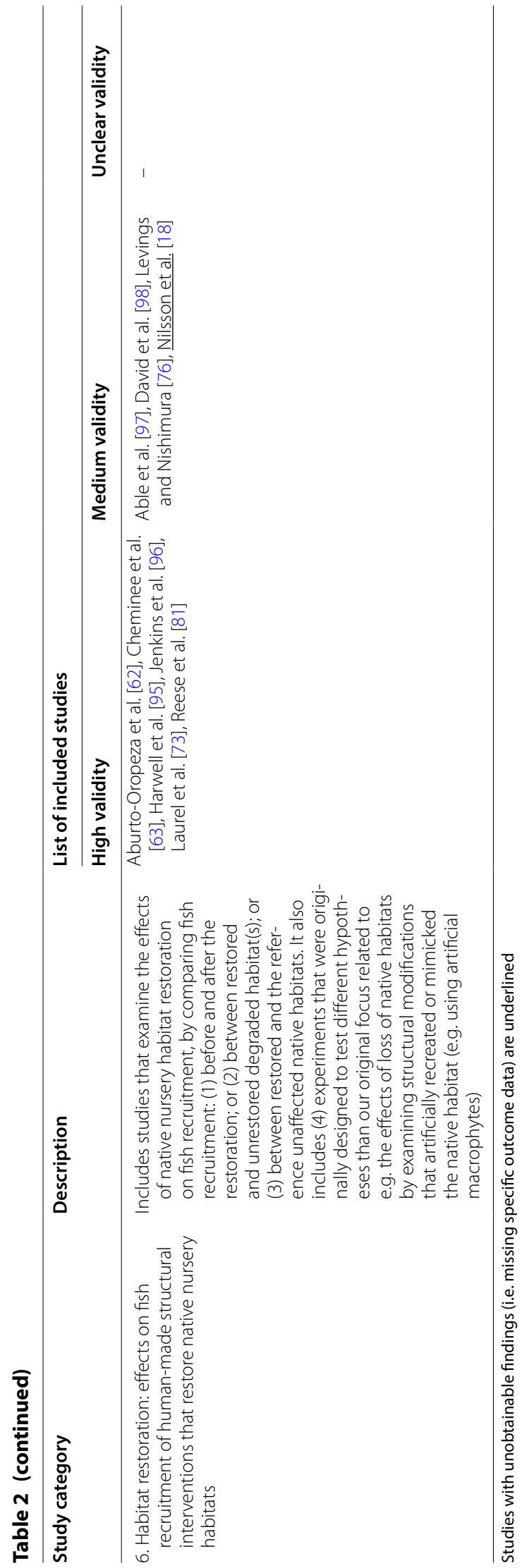


The response of fish recruitment to the introduction of human-made structures varied between species and type of exposure; the results varied even within close speciesgroups, such as salmonids, and between different studies from the same areas. In the study of Clynick [64], findings were species-specific, dependent on recruitment stage and if sampling was performed at exposed or sheltered sides of breakwaters. Newly recruited two-banded seabream (Diplodus vulgaris) was more abundant on sheltered side of breakwaters, and absent from exposed sides of breakwaters and adjacent rocky reef. In contrast, two-banded sea bream and Mediterranean rainbow wrasse (Coris julis) juvenile abundances were not significantly different between exposed, sheltered breakwaters and rocky reefs. Toft et al. [85] found significantly higher density of juvenile salmonid species around overwater structures, and deep water ripraps in comparison to the surrounding natural habitat (sand and cobble beaches). Authors also identified species-specific responses: Chinook salmon (Oncorhynchus tshawytscha) juveniles had the highest densities around deep water riprap while densities of juvenile Chinook-Coho salmon (O. tshaw$y$ tscha-O. kisutch) were the highest around overwater structures, but there were no differences in juvenile density between areas with deep-water ripraps and natural cobble and sandy beaches. Rodrigues and Vieira [60] did not found any differences in juvenile abundances of studied species between areas with rocky jetties and adjacent beaches. Similarly, Scyphers et al. [86] did not find any differences in abundance of juvenile sciaenids between areas with breakwaters built with oyster shells compared to adjacent natural habitat. Two studies, Gristina et al. [87] and Stoklosar [77], found significantly higher abundances of long-snouted seahorse (Hippocampus guttula$t u s$ ) and juveniles of several species, respectively, in areas with human-made structures compared to reference areas without. These higher abundances were attributed to the presence of macroalgae. However, Stoklosar [77] showed that higher abundances of juvenile fish were only significant when assessed by trawl sampling; not when assessed with traps. Pondella and Stephens [80], compared fish communities before and after rebuilding of a harbour. Only one species (Garibaldi damselfish (Hypsypops rubicundus)) showed significantly lower abundance during the rebuilding event, compared to both before or after, while all other species showed no significant variation during the study period. Finally, Wehkamp and Fischer [69] did not conduct statistical analysis to compare for differences between juvenile abundances on and around tetrapods.

\section{Fish attractors: structures designed to locally enhance fishery resources by providing or recreating habitat for fish}

This category differs from the previous one as the structures were designed for and deliberately introduced into the environment to enhance fish abundance. Analogous to the previous group, fish recruitment was compared before and after the impact or between affected and unaffected area(s).

This category included three studies from marine coastal ecosystems in Sweden [79], Canada [88] and Chile [68]. Two studies were judged to have high validity $[79,88]$ and medium validity was assigned to the Jara and Cespedes study [68] (due to lack of independence between observational units). All the studies were experimental with CI design, except the Jara and Cespedes [68] study which had a BACI design. Sampling was done during one [79] or 2 years $[68,88]$. Human-made habitat alterations ranged from spruce bundle structures [79] to concrete artificial structures $[68,88]$ introduced to low complexity substrate (sparse submerged vegetation or sand, gravel, or small cobble respectively). Reported outcomes were abundance of individual juvenile species.

There was only limited evidence that artificial substrates that were added to enhance fish recruitment had the intended effect, and this was further restricted to specific environmental context. In Sandström et al. [79] fish recruitment response varied according to water clarity: in clear waters fish abundance was significantly higher in spruce bundles with surrounding net then in control areas (i.e. surrounding native habitats), while in turbid waters there were no statistically significant differences. Sargent et al. [88] showed no significant differences in abundances between artificial reefs and control transects. Jara and Cespedes [68] did not conduct statistical tests to compare differences between juvenile abundances on reefs and control areas.

\section{Urban sprawl: effects potentially leading to native habitat deterioration and loss over large (regional or national) spatial scales}

This category included studies evaluating the impact of undefined human development or structural modification over large coastal areas by comparing fish recruitment before and after historical coastal development or between urbanised vs moderately urbanised or undeveloped control regions(s).

This category included three studies from Sweden (one study, [78]) and USA (two studies [58, 66]). Two studies were in marine $[66,78]$, and one study in a large lacustrine ecosystem [58]. All three studies were judged to have high validity. They were all large scale observational studies with CI design. Sampling was done during one 
[58] or two consecutive seasons [66]; or nine consecutive years [78].

Hansen and Snickars [78] compared gradients of very low, low, and high levels of anthropogenic pressure (including boating-related infrastructure and boat traffic) that affect macrophyte community and juvenile fish abundances. Brazner [58] compared developed (i.e. modified by physical alterations created by dikes, landfills, homes, or industry) to undeveloped sites for two different habitat types (wetlands and beaches). Chittaro and colleagues [66] compared degraded and highly modified urban shorelines (located in proximity to populated areas) with less altered shorelines for their contribution as nursery areas in the region. Reported outcomes are abundance of juveniles of individual species or species groups.

The studies indicate that vegetation and wetlands are important for fish recruitment, but only two studies provide analysable data which strongly limits our ablity to draw any conclusions. Brazner [58], found that one species [bluegill (Lepomis macrochirus)] out of seven had significantly lower densities in developed wetlands compared to undeveloped wetlands, but no statistical differences between urban developed beaches and undeveloped beaches were found for any of the species. Chittaro et al. [66] did not conduct statistical analysis to compare differences in urban versus non-urban areas, and did not provide data in a sufficient detail to statistically test for differences. Hansen and Snickars [78] showed juvenile fish abundance significantly and positively related to indexes of increasing macrophyte cover, which are scarce or lost in urban developed areas.

\section{4. "Novel" habitats: performance of human-made structures as nursery habitats compared to structurally similar natural habitats}

Studies in this category assessed how introduced humanmade structures perform as novel fish habitats in comparison to adjacent and structurally similar natural habitats. These studies examined which species colonise or use these novel structures. The category included studies that evaluate the potential nursery value of: (1) coastal infrastructures such as breakwaters, jetties, seawalls, etc., and (2) artificial reefs or other structures primarily designed to enhance habitat complexity and provide habitat for fish species. The comparator in these studies was the natural habitat with the most similar characteristics to the exposure (e.g. breakwaters compared to rocky reefs). Some studies further explored how specific elements of the design or location of the structures can increase their nursery value.

This category included nine studies from marine coastal ecosystems [59, 61, 65, 67, 74, 75, 82, 89-91].
Most of the studies were located in the Northern hemisphere (eight), and in the USA (five, $[65,74,75,82,89$, 90]), followed by France (two, $[67,91]$ ) and China (one, [61]). In the Southern hemisphere there was only one study from Australia [59]. Studies varied in validity. Medium validity was assigned due to issues with the design such as lack of independence between observational units (pseudoreplication) $[82,91]$ and unbalanced sampling design [67]. Five studies were experimental [59, $65,67,74,75,90]$, and 4 were observational $[61,82,89$, 91]. All studies had CI design. Apart from two studies $[65,82]$, sampling was done for a year or more. Exposures range from concrete artificial reef modules $[61,65,67,74$, $75,82,89]$, mussel farms [61] and oyster grow-out cages [90], to breakwaters $[59,91]$ and seawalls [91]. Reported outcomes were abundance of juveniles of individual or group of species.

The reported results on juvenile fish abundance around human-made structures, in comparison to natural reefs, was not consistent and varied among studies, systems and fish species. Among six studies of concrete artificial reefs, two $[65,67]$ did not carry out statistical analyses to test for differences. Reed et al. [74, 75] and Wang et al. [61] found higher densities of YOY fish on artificial reefs compared to natural rocky-reefs. In contrast, Matthews [89] found no statistically significant difference between artificial and natural rocky reefs. Jessee et al. [82] demonstrated species-specific differences in juvenile fish abundance between artificial and natural reefs: California sheephead (Semicossyphus pulcher) and black perch (Embiotoca jacksoni) had higher densities on artificial reef, whereas no significant differences in densities of halfmoon (Medialuna californiensis), kelp bass (Paralabrax clathratus), opaleye (Girella nigricans) and barred sand bass (Paralabrax nebulifer) were found. Effects on recruitment of breakwaters also varied. Fowler and Booth [59] found species-specific responses: no significant difference between breakwaters and natural rocky reef for abundances of juvenile silver sweep (Scorpis lineolate) and other juveniles combined, while higher abundance of Australian mado (Atypichthys strigatus) on breakwaters when compared to natural rocky reef was found. Pastor et al. [91] found higher abundance of juvenile white sea bream (Diplodus sargus) on breakwaters. Tallman and Forrester [90] found age-specific responses, densities of age-1 and 1+ scup (Stenotomus chrysops) were significantly higher on oyster cages than on natural reefs, while density of age- 0 did not show any statistically significant difference. Additionally, in Wang et al. [61], abundance of juvenile fish did not differ statistically between mussel farms and natural rocky reefs. 


\section{Habitat loss: experimentally measured effects of native (nursery) habitat loss as a direct consequence of urban sprawl}

In contrast to category 3 , this category included experiments that were specifically designed to simulate the effects of human-made developments and urban sprawl on native habitat structure and cover, such as for example, kelp removal experiments. Note that studies that broadly focused on habitat loss without making a specific link to urban and coastal development were not considered in our review.

This category included four studies from marine coastal ecosystems in the USA [92-94] and Canada [73]. All studies had experimental CI design, except for a study by Laurel et al. [73] that had a BACI design. All studies in this category had high validity. Sampling lasted from one [93] or 3 months [92] to several years [73, 94]. Studies examined the effects of: surfgrass removal from reefs compared to unaffected control reefs [92]; eelgrass removal compared to unaffected eelgrass control areas [73]; and manipulation of percentage of macroalgae cover [93, 94] or type of macroalgae cover within a kelp bed [93]. Reported outcomes were abundance of individual juvenile species. The studies in this category were limited in scale and not comparable to each other due to varying designs. The effect of removing natural recruitment habitat on juvenile fish abundances was inconsistent. Galst and Anderson [92] found species-specific responses of removing surfgrass: densities for total recruits, blacksmith (Chromis punctipinnis) and señorita (Oxyjulis californica) were higher on undisturbed areas, whereas giant kelpfish (Heterostichus rostratus) had higher densities on disturbed areas, and rock wrasse (Halichoeres semicinctus) did not show any significant response. Laurel et al. [73] showed decrease in abundance of age-0 Atlantic cod (Gadus morhua) and Greenland cod (G. ogac) following the removal of eelgrass, while abundances recovered over time to pre treatment levels. Levin [93] found no significant difference in YOY cunner (Tautogolabrus adspersus) density between habitats with all algae or canopy removed and control areas. O'Connor and Anderson [94] showed significant decline in one species immediately after thinning of kelp, but not for any other species. After the kelp regenerated, all significant effects on fish by the thinning treatment disappeared.

\section{Habitat restoration: effects through structural interventions that restore native nursery habitats}

This category included studies that examined the effects of native nursery habitat restoration on fish recruitment, by comparing fish recruitment: (1) before and after the restoration, or (2) between restored and unrestored degraded habitat(s), or (3) between restored and the reference unaffected native habitats. It also included four experiments that were originally designed to test different hypotheses (often related to the effects of loss of native habitats) but did this by structural interventions that recreated artificially the habitat or a mimic of it (e.g. using artificial macrophytes), thereby providing tests that we interpreted as potentially informative for restoration effectiveness. Some artificial reef designs were also meant to restore specific habitats (e.g. [74, 75]) but we listed some of those in category 4.

This category included 10 studies, all from marine coastal ecosystems $[18,62,63,73,76,81,95-98]$. The majority of these studies were located in the Northern hemisphere (nine), and in the USA (four $[81,95,97,98]$ ), followed by Canada (two, [73, 76]), Mexico (one, [62]), France (one, [63]) and Sweden (one, [18]). In the Southern hemisphere there was only one study from Australia [96]. Studies varied in the validity: six were judged to have high validity $[62,63,73,81,95,96]$ and four were assigned medium validity $([18,76,97,98])$. Medium validity was assigned due to unbalanced sampling design [76], pseudoreplication [97], differences between samples [98] and lack of spatial control [18]. There were no studies with unclear validity.

Most of the studies were experimental (8), with the exception of two observational studies $[18,76]$. Most of the studies (seven) were designed as CI, except Laurel et al. [73] with a BACI design, and Reese et al. [81] and Nilsson et al. [18] designed as BA studies. Apart from three studies $[62,63,97]$, where sampling was limited to one year, the studies lasted for a longer time period.

Four of the studies examined wetland or marsh restoration [18, 76, 97, 98]. Laurel et al. [73] and Jenkins et al. [96] examined the effectiveness of the artificial eelgrass units for fish recruitment, whereas Cheminee et al. [63] and Aburto-Oropeza et al. [62] experimentally tested effects on juvenile abundance from restoration of macrophyte coverage using artificial and natural macrophyte manipulations. Harwell et al. [95] studied the potential of oyster reef restoration for fish abundance. Reese et al. [81] compared estuarine-dependent recruitment in seagrass habitats pre- and post-opening of an adjacent tidal inlet closed for a long time. The reported outcomes were abundance of individual juvenile fish species. Restoration efforts of macrophytes, with transplants or artificial macrophyte mimics including Sargassum [62], Cystoseira spp. (only for one species of fish, [63]), artificial seagrass [73, 96], and Spartina [97] in general showed positive effects on the abundance of juvenile fish compared to bare, disturbed or invaded habitats. In contrast, Harwell et al. [95] showed no significant differences in juvenile fish abundance between created oyster reefs, reference natural reefs or mudflats. Restoration of marshes or tidal 
inlets showed varying effects, depending on the choice of reference sites. Reese et al. [81] showed significantly higher density of fish recruits the year after the opening of the tidal inlet. In contrast, David et al. [98] showed significantly lower densities in the two restored channels compared to two reference channels, although densities increased over time. Finally, Levings and Nishimura [76] reported no statistically significant differences between the restored marsh site and the control. Nilsson et al. [18] did not statistically test differences in numbers of emigrating E. lucius before and after restoration.

\section{Discussion}

This systematic review aimed to estimate the impacts on fish recruitment of various human-made structural modifications of temperate and Arctic coastal marine, brackish and large lake habitats (both in the Northern and Southern Hemispheres). Our review shows that the impact (e.g. studies in categories 1 and 2) and ecological performance (category 4) of structural modifications are context and species dependent. In the following sections we will describe and discuss reasons for heterogeneity, limitations of the evidence base and limitations of the review methodology.

\section{Reasons for heterogeneity}

In the first category, which evaluates the impact of human-made structures on local modification, degradation or loss of native nursery habitat, fish recruitment response varied with specific type of studied structure and species studied (even within related species group) and between new recruits and juveniles. For example, juvenile fish responses were affected by the presence (or absence) of macroalgae on artificial structures, where presence of macroalgae on the constructions had a positive effect on juvenile abundance (e.g. [77, 87]). Sampling methods (e.g. [77]) also introduced differences in measured recruitment response. The second category dealt with human-made structures designed to locally enhance fishery resources by providing or recreating habitats for fish. The evidence base was limited to 3 studies (that had different designs) and we were only able to obtain findings from two of them. In one of the studies, recruitment response also varied due to environmental factors as positive effects on recruitment by adding artificial structures was only observed in clear water but not in turbid water [79]. The third category evaluated the impact on fish recruitment of urban sprawl over larger (regional or national) spatial scales. The evidence base here was also limited, and it included three studies from different geographical locations, marine and freshwater systems. In this category, findings were obtained from the two studies and they showed the presence of vegetation in impacted areas to be a potentially important (and positive) factor for recruitment. The fourth category gathered studies that evaluated performance of human-made structures as nursery habitats for fish recruitment (in comparison to structurally similar natural habitats). Types of structures and habitats compared in the different studies varied substantially, and the outcome from included studies varied mainly from positive, e.g. higher densities on artificial reefs and breakwaters compared to natural reefs [59, $61]$ to no effect $[82,89]$ across species. The fifth category dealt with experiments designed to measure effects on fish recruitment of nursery habitat loss. However, this evidence base was also limited to 4 studies with varying study designs like kelp [93] or surf grass removal [92] and species-specific outcomes showing positive, negative or no effect of the removal. The final category of studies examined the effects of native nursery habitat restoration with substantial variation in their study designs, validity and type of restoration, e.g. oyster reef [95] and tidal channel restoration [81] to artificial eel grass additions [96]. In sum, the results of this review show that the evidence base for the impact on recruitment of coastal modifications is limited and general conclusions are difficult to make, due to: (1) the heterogeneity of studies that were either context- or species-specific; and (2) the limited spatial and temporal scales of studied effects.

\section{Review limitations}

Although the importance of coastal habitats to fish population abundance and fishery yield of commercially and ecologically important species has been demonstrated (e.g. [16]), our assessment showed a surprising lack of information about how structural modifications and changes over a broad range of coastal and estuarine habitats (related to marine urban sprawl) can affect fish recruitment. Here, we defined recruitment broadly as absolute or relative abundance of juvenile fish, mainly YOY fish, but also older juveniles. While we argue that we took a broad inclusive approach, we ended up with an unexpectedly small number of comparable studies (55 studies included at full text, with 37 studies finally included after critical appraisal, but divided over six categories). The reasons for this limited number of studies could be related to either methodological limitations of our review, limitations of the evidence base, or both.

\section{Limitations of the review methodology}

This review had a focused search strategy devised deliberately to capture effects of urbanization and humanmade structures and structural modifications of nursery and spawning habitats of fish, as requested by the stakeholders. It does not include effects of habitat changes associated with invasive species, storms, tsunamis, 
climate change, or sea level rise. Although we searched for literature in seven languages, we might have missed some studies. For example, searches in French, Russian and Chinese were not included. France, Russia and China are countries with significant numbers of state-financed research institutes and universities and also with a commercial interest in temperate coastal fisheries, indicating the presence of potential reports investigating impacts on recruitment that we likely missed. Moreover, longterm unreplicated environmental monitoring studies would not be eligible for our review, but still such studies may have the potential to show the long-term impact of human-made structures, revealing population trends.

Another limiting factor is the different definitions and conventions on how to measure fish recruitment. There were likely numerous studies that test effects of humanmade structures on the very early life stages that were not included in our review (e.g. we excluded 178 studies at full text screening stage for not including data on juvenile or YOY fish). We chose not to include these since it is unclear how effects on eggs and larvae translates to effects on recruitment, as the relation between the very early life-stages and YOY abundance can be limited and certainly very context dependent (and less so than the later stages) [99].

This review was based on the request from Swedish stakeholders and our primary objective was to provide evidence relevant to the Baltic sea context. Therefore, we included comparable marine, brackish and large freshwater systems $\left(>10,000 \mathrm{~km}^{2}\right)$. However, we might have gained additional insights if we have also included studies from smaller lakes (see [100]) or non-temporal regions.

\section{Limitations of the evidence base}

We observed that studies tend to focus on the connections either between human-induced structural changes and the status of coastal habitats (e.g. [101-103]) or between the status of coastal habitats and fish recruitment (e.g. [104-106]), while comparatively far fewer studies make direct connection between structural changes and fish recruitment.

Possibly the major limitation of obtained evidence base is also the most informative result; that there is a large mismatch between available published research and stakeholder needs. Only nine studies were found in category 1 (the main question for the stakeholders), of which five studies were judged to be of high validity. A larger evidence base was found in category 4 with the focus on structures deliberately introduced to enhance recruitment (10 studies, six with high validity) and category 6 focusing on restoration interventions (10 studies, six with high validity).
Despite available guidance on how to conduct rigorous assessment of impacts [107], poorly designed studies are still being done and impacts are still being erroneously or incompletely assessed. There was a surprisingly small number of BACI studies (three in total) and thus, most studies included in this review assess the impact of coastal structures on fish recruitment without prior baseline data from the impacted and control areas.

Additionally, most studies had limited temporal and spatial resolution. We found only three studies that examined habitat modifications across large spatial scales to estimate system-wide effects (study category 3, [58, $66,78]$ ). They explored effects on regional scales, such as impacts on the recruitment in an archipelago or estuary by accumulated changes in the physical habitat, compared to the recruitment in an area with intact natural spawning and nursery habitats. Additionally, only five studies measured the effects of the habitat modification over longer period (more than 4 years) $[73-75,78,80]$. Although such large-scale studies are labour-intensive and expensive, we believe they are essential for understanding effects of human development on fish recruitment. Despite their scientific rigour, results of studies that measure impacts at small scales may be difficult to extrapolate at the scale needed to inform decisions about conservation and fisheries management [108]. Moreover, eleven studies had to be excluded from our synthesis mainly because reported juvenile data was not separable from adult fish data. Availability of raw data as supplementary material in such circumstances would have been valuable for this synthesis.

\section{Review conclusions}

\section{Implications for policy and management}

It has become apparent that identifying and quantifying impacts on fish recruitment of native coastal habitat loss and the nursery value of a variety of coastal and estuarine habitats are needed [17, 109-112]. In this context habitat structure and complexity are emerging as critical factors influencing nursery values of coastal habitats $[16,113,114]$. Human-induced changes in habitat structure are one of the main pressures affecting estuarine and coastal systems worldwide [10,12], yet our review clearly shows that the degree and rate of these changes and their impact on fish recruitment are rarely studied and poorly understood. Efforts need to focus on how to mitigate the impacts that do occur, take into account the affected habitats, and exploit opportunities [115]. The limited evidence base complicates policy making and point to the need for more well-designed studies on this issue, otherwise there is a risk of implementing policy decisions based on the lack of evidence of negative (or no) effects and ignoring a precautionary approach in favour 
of societal growth and development. Of course, there is also an economic opportunity cost of preventing societal development based on concerns for fish if such effects are not present. Given the different responses of different species in different habitats (e.g. [59, 64, 91]) there is also the risk of inferring results from one or a few studies to support management decisions that may not deliver the desired results. The lack of evidence and the high heterogeneity that we show in this review point to the complexity of the issue and should motivate more investment in targeted research towards evaluating the value of coastal habitats [16], impacts of human activities on these habitats [116] and finally link the pressures (coastal habitat reconstruction) with fish recruitment. Only then can managers implement evidence-based regulations of human activities, mitigate effects, and execute compensatory actions for these activities. The planning of these compensatory actions can only take place if there is sufficient knowledge on what conditions are necessary to maintain or restore ecosystem function.

\section{Implications for research}

This review revealed a substantial mismatch between stakeholder needs and research evidence on effects on fish recruitment from physical anthropogenic impacts on coastal habitats. Hence, there is an urgent need for more investigations that not only study effects of specific and multiple exposures and interventions but also study how structures can be made or modified to provide adequate ecological functions.

Long-term studies are rare but due to the large year-toyear variation in recruitment in many fish species [117], longer term measurements before and after a modification should be collected. The modifications should have appropriate, matching control areas to control for spatial variability. Clearly, this variability calls for a BACI design and such studies would substantially increase our collective understanding of the effects of coastal development. Thus, when possible, sampling should be conducted in the affected area both before and after the intervention. Even so, the vast number of existing anthropogenic habitat modifications provides plenty of opportunities to conduct well replicated CI studies. Here, special attention should be taken to assure independence of measurement between replicates and that exposure and controls are well-matched.

Another important consideration is that recruitment is a complex process where abiotic and biotic factors may have very different impact on different life stages normally associated with recruitment process (e.g. eggs, larvae and juvenile fish) [117]. Thus, studies focusing on single exposures may show effects on a certain life-history stage of juvenile fish, but this effect may have no discernible effect on overall recruitment $[118,119]$. Reasons for this could be that juvenile fish are performing ontogenetic niche shifts and thereby actively change habitats to e.g. open water, or because bottlenecks in recruitment are not associated with the nearshore habitats studied. This is exemplified by the discussion on ocean versus freshwater stages affecting salmon returns in the Pacific [120], or by the discussion on whether processes occurring during the offshore egg/larval stages versus the post-settlement stages in the coastal areas affect recruitment in several marine flatfish [121, 122]. Identifying presence or absence of bottlenecks in different life stages is important, but these bottlenecks will occur at different life stages for different fish species [99], making general conclusions difficult.

Another way to improve the evidence base on the potential impacts of human-made structures and structural modifications is to use studies of smaller lakes (but see [106]), as potential impacts on recruitment may be easier to observe when the impact itself is larger compared to the size of the ecosystem and when the impacted fish population is confined. Finally, researchers reporting on their outcomes should always publish variances and sample sizes or provide raw data in an electronic appendix so their data can be used in meta-analyses.

\section{Additional files}

Additional file 1. ROSES form for systematic reviews.

Additional file 2. Search strategy.

Additional file 3. Narrative table.

Additional file 4. Studies excluded due to low validity.

Additional file 5. Data extraction with statistical analysis.

Additional file 6. List of unobtainable articles.

Additional file 7. List of excluded articles at full text screening.

Abbreviations

YOY: young-of-the year; BACl: before-after-control-impact; Cl: controlimpact; BA: before-after.

\section{Authors' contributions}

$B M$ with the review team searched, extracted and synthesised available evidence. BM, PB, LA, BKE, LR and JS critically appraised studies. BM and PB drafted the manuscript, together with $L A, B K E$, LR and JS. All authors read and approved the final manuscript.

\footnotetext{
Author details

${ }^{1}$ Mistra Council for Evidence-Based Environmental Management (EviEM), Stockholm Environment Institute, Linnégatan 87D, Box 24218, 10451 Stockholm, Sweden. ${ }^{2}$ Department of Ecology and Environmental Science, Faculty of Science and Technology, Umeå University, 90187 Umeå, Sweden. ${ }^{3}$ Department of Biological, Geological and Environmental Sciences and Interdepartmental Research Centre for Environmental Sciences, UO CoNISMa, University of Bologna, Via S. Alberto 163, 48123 Ravenna, Italy. ${ }^{4}$ Groningen Institute for Evolutionary Life-Sciences, Marine Ecology, University of Groningen, Nijenborgh 7, 9747 AG Groningen, The Netherlands. ${ }^{5}$ Cornell Biological Field Station, Department of Natural Resources, Cornell University, 900 Shackelton Point Road, Bridgeport, NY 13030, USA. ${ }^{6}$ National Institute of Aquatic Resources, Technical University of Denmark, Kemitorvet, 2800 Kgs. Lyngby, Denmark.
} 


\begin{abstract}
Acknowledgements
We thank authors that provided raw data (John C. Brazner, Fábio Lameiro Rodrigues, Daniel C. Reed, Joakim P. Hansen) or clarifications connected to their studies (Jason D. Toft and Philipp Fischer). We are grateful for help with screening and article retrieval provided by Filippa Ek, Nichlas Staberg and Mårten Söderquist. Additionally, many thanks to Kevin Vikström for Finnish grey literature searching and screening, Sebastian Diehl for screening of studies in German language, Filippa Ek for extraction of data and metadata and Tom Gill for proofreading. Finally, we thank two anonymous reviewers whose comments helped improve and clarify this manuscript.
\end{abstract}

\section{Competing interests}

The authors declare that they have no competing interests. Authors involved in this review that also authored articles relevant for this review did not have any role in the screening, data extraction, or critical appraisal of those articles.

\section{Availability of data and materials}

The dataset supporting the conclusions of this article is included within the article (and its additional files).

\section{Consent for publication}

Not applicable.

\section{Ethics approval and consent to participate}

Not applicable.

\section{Funding}

This review is financed by the Mistra Council for Evidence-based Environmental Management (EviEM)

\section{Publisher's Note}

Springer Nature remains neutral with regard to jurisdictional claims in published maps and institutional affiliations.

Received: 29 May 2018 Accepted: 5 March 2019

Published online: 12 March 2019

\section{References}

1. Halpern BS, Walbridge S, Selkoe KA, Kappel CV, Micheli F, D'Agrosa C, Bruno JF, Casey KS, Ebert C, Fox HE, et al. A global map of human impact on marine ecosystems. Science. 2008;319:948-52.

2. Bulleri F, Chapman MG. The introduction of coastal infrastructure as a driver of change in marine environments. J Appl Ecol. 2010;47:26-35.

3. Duarte CM, Pitt KA, Lucas CH, Purcell JE, Uye S-I, Robinson K, Brotz L, Decker MB, Sutherland KR, Malej A, et al. Is global ocean sprawl a cause of jellyfish blooms? Front Ecol Environ. 2013;11:91-7.

4. Sundblad G, Bergström U. Shoreline development and degradation of coastal fish reproduction habitats. Ambio. 2014;43:1020-8.

5. Beck MW, Heck KL, Able KW, Childers DL, Eggleston DB, Gillanders BM, Halpern B, Hays CG, Hoshino K, Minello TJ, et al. The identification, conservation, and management of estuarine and marine nurseries for fish and invertebrates. Bioscience. 2001;51:633-41.

6. Larsson P, Tibblin P, Koch-Schmidt P, Engstedt O, Nilsson J, Nordahl $\mathrm{O}$, Forsman A. Ecology, evolution, and management strategies of northern pike populations in the Baltic Sea. Ambio. 2015:44(Suppl. 3):S451-61.

7. Heery EC, Bishop MJ, Critchley LP, Bugnot AB, Airoldi L, Mayer-Pinto M, Sheehan EV, Coleman RA, Loke LHL, Johnston EL, et al. Identifying the consequences of ocean sprawl for sedimentary habitats. J Exp Mar Biol Ecol. 2017:492:31-48.

8. Bishop MJ, Mayer-Pinto M, Airoldi L, Firth LB, Morris RL, Loke LHL, Hawkins SJ, Naylor LA, Coleman RA, Chee SY, et al. Effects of ocean sprawl on ecological connectivity: impacts and solutions. J Exp Mar Biol Ecol. 2017:492:7-30.

9. Peterson CH, Bishop MJ, D'Anna LM, Johnson GA. Multi-year persistence of beach habitat degradation from nourishment using coarse shelly sediments. Sci Total Environ. 2014;487:481-92.
10. Airoldi L, Beck MW. Loss, status and trends for coastal marine habitats of Europe. In: Gibson RN, Atkinson RJA, Gordon JDM, editors. Oceanography and marine biology, vol. 45. 2007. p. 345-405.

11. Airoldi L, Turon X, Perkol-Finkel S, Rius M. Corridors for aliens but not for natives: effects of marine urban sprawl at a regional scale. Divers Distrib. 2015;21:755-68.

12. Lotze HK, Lenihan HS, Bourque BJ, Bradbury RH, Cooke RG, Kay MC, Kidwell SM, Kirby MX, Peterson CH, Jackson JBC. Depletion, degradation, and recovery potential of estuaries and coastal seas. Science. 2006:312:1806-9.

13. Lotze HK. Historical reconstruction of human-induced changes in U.S. estuaries. Oceanogr Mar Biol Ann Rev. 2010;48:267-338.

14. HELCOM. Ecosystem health of the Baltic Sea: HELCOM Initial Holistic Assessment. In: Baltic Sea Environment Proceedings, vol. 122. 2010. p. 1-63.

15. Ljunggren L, Sandstrom A, Johansson G, Sundblad G, Karas P. Problems of recruitment in Baltic Sea fish stocks. Finfo Fiskeriverket Informerar. 2005;5:1-45.

16. Seitz RD, Wennhage $H$, Bergström U, Lipcius RN, Ysebaert T. Ecological value of coastal habitats for commercially and ecologically important species. ICES J Mar Sci. 2014:71:648-65.

17. Nagelkerken I, Sheaves M, Baker R, Connolly RM. The seascape nursery: a novel spatial approach to identify and manage nurseries for coastal marine fauna. Fish Fish. 2015;16:362-71.

18. Nilsson J, Engstedt O, Larsson P. Wetlands for northern pike (Esox lucius L.) recruitment in the Baltic Sea. Hydrobiologia. 2014;721:145-54.

19. Sandström A, Eriksson BK, Karås P, Isæus M, Schreiber H. Boating and navigation activities influence the recruitment of fish in a Baltic Sea archipelago area. Ambio. 2005;34:125-30.

20. Eriksson BK, Sandstrom A, Isæus M, Schreiber H, Karas P. Effects of boating activities on aquatic vegetation in the Stockholm archipelago, Baltic Sea. Estaur Coast Shelf Sci. 2004:61:339-49.

21. ICES. Report of the Baltic fisheries assessment working group (WGBFAS). ICES CM 2014/ACOM: 10. 2014

22. Olsson J, Bergström L, Gårdmark A. Abiotic drivers of coastal fish community change during four decades in the Baltic Sea. ICES J Mar Sci. 2012;69:961-70.

23. Adjers K, Appelberg M, Eschbaum R, Lappalainen A, Minde A, Repecka $\mathrm{R}$, Thoresson $\mathrm{G}$. Trends in coastal fish stocks of the Baltic Sea. Boreal Environ Res. 2006;11:13-25.

24. Tulp I, Bolle LJ, Rlinsdorp AD. Signals from the shallows: in search of common patterns in long-term trends in Dutch estuarine and coastal fish. J Sea Res. 2008:60:54-73.

25. Eriksson BK, Sieben K, Eklöf J, Ljunggren L, Olsson J, Casini M, Bergström U. Effects of altered offshore food webs on coastal ecosystems emphasize the need for cross-ecosystem management. Ambio. 2011:40:786-97.

26. Jackson JBC, Kirby MX, Berger WH, Bjorndal KA, Botsford LW, Bourque BJ, Bradbury RH, Cooke R, Erlandson J, Estes JA, et al. Historical overfishing and the recent collapse of coastal ecosystems. Science. 2001;293:629-38.

27. Shohidullah MM. Climatic and anthropogenic factors changing spawning pattern and production zone of Hilsa fishery in the Bay of Bengal. Weather Clim Extremes. 2015:7:109-15.

28. Pikitch EK, Rountos KJ, Essington TE, Santora C, Pauly D, Watson R, Sumaila UR, Boersma PD, Boyd IL, Conover DO, et al. The global contribution of forage fish to marine fisheries and ecosystems. Fish Fish 2014;15:43-64.

29. Österblom H, Hansson S, Larsson U, Hjerne O, Wulff F, Elmgren R, Folke C. Human-induced trophic cascades and ecological regime shifts in the Baltic Sea. Ecosystems. 2007;10:877-89.

30. Hiddink JG, Jennings S, Kaiser MJ, Queirós AM, Duplisea DE, Piet GJ. Cumulative impacts of seabed trawl disturbance on benthic biomass, production, and species richness in different habitats. Can J Fish Aquat Sci. 2006;63:721-36.

31. Andersson J, Dahl J, Johansson A, Karås P, Nilsson J, Sandström O, Svensson P. Utslagen fiskrekrytering och sviktande fiskbestånd i Kalmar läns kustvatten. Fiskeriverket. 2000.

32. Kallasvuo M, Vanhatalo J, Veneranta L. Modeling the spatial distribution of larval fish abundance provides essential information for management. Can J Fish Aquat Sci. 2017;74:636-49. 
33. Lehtonen H, Leskinen E, SelÉN R, Reinikainen M. Potential reasons for the changes in the abundance of pike, Esox lucius, in the western Gulf of Finland, 1939-2007. Fish Manag Ecol. 2009;16:484-91.

34. Nilsson J, Andersson J, Karas P, Sandstrom O. Recruitment failure and decreasing catches of perch (Perca fluviatilis L.) and pike (Esox lucius $\mathrm{L}$.) in the coastal waters of southeast Sweden. Boreal Environ Res. 2004;9(4):295-306.

35. Sundblad G, Bergström U, Sandström A, Eklöv P. Nursery habitat availability limits adult stock sizes of predatory coastal fish. ICES J Mar Sci. 2014;71:672-80

36. Ljunggren L, Sandström A, Bergström U, Mattila J, Lappalainen A, Johansson G, Sundblad G, Casini M, Kaljuste O, Eriksson BK. Recruitment failure of coastal predatory fish in the Baltic Sea coincident with an offshore ecosystem regime shift. ICES J Mar Sci. 2010;67:1587-95.

37. Byström P, Bergström U, Hjälten A, Ståhl S, Jonsson D, Olsson J. Declining coastal piscivore populations in the Baltic Sea: where and when do sticklebacks matter? Ambio. 2015;44(Suppl 3):462-71.

38. Halpern BS, Gaines SD, Warner RR. Habitat size, recruitment, and longevity as factors limiting population size in stage-structured species. Am Nat. 2005:165:82-94.

39. Ljunggren L, Olsson J, Nilsson J, Stenroth P, Larsson P, Engstedt O, Borger T, Sandstrom O. Water courses as recruitment areas for pike in the Baltic Sea. Experiences and recommendations from the research project. Finfo Fiskeriverket Informerar. 2011;1:1-63.

40. Stål J, Paulsen S, Pihl L, Rönnbäck P, Söderqvist T, Wennhage H. Coastal habitat support to fish and fisheries in Sweden: integrating ecosystem functions into fisheries management. Ocean Coast Manag. 2008:51:594-600.

41. Rönnbäck P, Kautsky N, Pihl L, Troell M, Söderqvist T, Wennhage H. Ecosystem goods and services from Swedish coastal habitats: identification, valuation, and implications of ecosystem shifts. Ambio. 2007;36:534-44.

42. Abelson A, Halpern BS, Reed DC, Orth RJ, Kendrick GA, Beck MW, Belmaker J, Krause G, Edgar GJ, Airoldi L, et al. Restoration of marine ecosystems: a need for ecological-social concept upgrade. Bioscience. 2016;66:156-63.

43. Pritt JJ, Roseman EF, O'Brien TP. Mechanisms driving recruitment variability in fish: comparisons between the Laurentian Great Lakes and marine systems. ICES J Mar Sci. 2014;71:2252-67.

44. Dauble AD, Heppell SA, Johansson ML. Settlement patterns of youngof-the-year rockfish among six Oregon estuaries experiencing different levels of human development. Mar Ecol Prog Ser. 2012;448:143-54.

45. Obaza A, Hoffman R, Clausing R. Long-term stability of eelgrass fish assemblages in two highly developed coastal estuaries. Fish Manag Ecol. 2015;22(3):224-38.

46. Pereira HH, Neves LM, da Costa MR, Araújo FG. Fish assemblage structure on sandy beaches with different anthropogenic influences and proximity of spawning grounds. Mar Ecol Evolut Persp. 2015;36(1):16-27.

47. Sheehan EV, Gall SC, Cousens SL, Attrill MJ, Stevens TF. Recovery of a temperate reef assemblage in a marine protected area following the exclusion of towed demersal fishing. PLoS ONE. 2013;8(12):e83883.

48. Macura B, Lönnstedt OM, Byström P, Airoldi L, Eriksson BK, Rudstam L, Støttrup J. What is the impact on fish recruitment of anthropogenic physical and structural habitat change in shallow nearshore areas in temperate systems? A systematic review protocol. Environ Evid. 2016;5:10.

49. Collaboration for Environmental Evidence. Guidelines and standards for evidence synthesis in environmental management. Version 5.0. In: Pullin AS, Frampton GK, Livoreil B, Petrokofsky G, editors. 2018. http:// www.environmentalevidence.org/information-for-authors. Accessed 20 Jan 2019.

50. Spalding MD, Fox HE, Allen GR, Davidson N, Ferdaña ZA, Finlayson M, Halpern BS, Al Lombana MAJ, Lourie SA, Martin KD, et al. Marine ecoregions of the world: a bioregionalization of coastal and shelf areas. Bioscience. 2007;57(7):573-83.

51. Kottek M, Grieser J, Beck C, Rudolf B, Rubel F. World Map of the KöppenGeiger climate classification updated. Meteorol Z. 2006;15(3):259-63.

52. EC. EC Directive 2000/60/EC of the European Parliament and of the Council of October 23, 2000 establishing a framework for community action in the field of water policy (L 327 of 22-12-2000).
53. Bernes C, Macura B, Gunnar Jonsson B, Junninen K, Müller J, Sandström J, Lōhmus A, Macdonald E. Manipulating ungulate herbivory in temperate and boreal forests: effects on vegetation and invertebrates. A systematic review. Environ Evid. 2018;7:13.

54. Akaike H. A new look at the statistical model identification. IEEE Trans Autom Control. 1974;19:716-23.

55. Team, RC. R: a language and environment for statistical computing Vienna: R Foundation for Statistical Computing. http://www.R-proje Ct.org/. 2013.

56. Bates D, Maechler M, Bolker B, Walker S. Fitting linear mixed-effects models using Ime4. J Stat Softw. 2015;67:1-48.

57. Wood SN. Fast stable restricted maximum likelihood and marginal likelihood estimation of semiparametric generalized linear models. J R Stat Soc B. 2011;73:3-36.

58. Brazner JC. Regional, habitat, and human development influences on coastal wetland and beach fish assemblages in Green Bay, Lake Michigan. J Great Lakes Res. 1997;23(1):36-51.

59. Fowler AM, Booth DJ. Seasonal dynamics of fish assemblages on breakwaters and natural rocky reefs in a temperate estuary: consistent assemblage differences driven by sub-adults. PLOS ONE. 2013:8:1-12.

60. Rodrigues FL, Vieira JP. Surf zone fish abundance and diversity at two sandy beaches separated by long rocky jetties. J Mar Biol Assoc UK. 2013;93:867-75.

61. Wang Z, Chen Y, Zhang S, Wang K, Zhao J, Xu Q. A comparative study of fish assemblages near aquaculture, artificial and natural habitats. J Ocean Univ China. 2015;14:149-60.

62. Aburto-Oropeza O, Sala E, Paredes G, Mendoza A, Ballesteros E, Ballesteros $E$. Predictability of reef fish recruitment in a highly variable nursery habitat. Ecology. 2007;88:2220-8.

63. Cheminee A, Sala E, Pastor J, Bodilis P, Thiriet P, Mangialajo L, Cottalorda $J M$, Francour P. Nursery value of Cystoseira forests for Mediterranean rocky reef fishes. J Exp Mar Biol Ecol. 2013;442:70-9.

64. Clynick BG. Assemblages of fish associated with coastal marinas in north-western Italy. J Mar Biol Assoc UK. 2006;86(4):847-52.

65. Wilson TC, Krenn SJ. Construction and evaluation of an artificial reef designed to enhance nearshore rockfish production. In: OCEANS'86. 1986. p. 547-51.

66. Chittaro Paul M, Finley Rachel J, Levin Phillip S. Spatial and temporal patterns in the contribution of fish from their nursery habitats. Oecologia. 2009;160:49-61.

67. Koeck B, Tessier A, Brind'Amour A, Pastor J, Bijaoui B, Dalias N, Astruch P, Saragoni $G$, Lenfant P. Functional differences between fish communities on artificial and natural reefs: a case study along the French Catalan coast. Aquat Biol. 2014;20(3):219-34.

68. Jara F, Céspedes R. An experimental evaluation of habitat enhancement on homogeneous marine bottoms in southern Chile. Bull Mar Sci. 1994;55(2-3):295-307.

69. Wehkamp S, Fischer P. Impact of coastal defence structures (tetrapods) on a demersal hard-bottom fish community in the southern North Sea. Mar Environ Res. 2013;83:82-92.

70. Bivand R, Keitt T, Rowlingson B. rgdal: Bindings for the 'geospatial' data abstraction Llbrary. R package version 1.2-16. 2017.

71. Borenstein M, Hedges LV, Higgins JPT, Rothstein HR. Chapter 40: when does it make sense to perform a meta-analysis? In: Introduction to Meta-Analysis. London: Wiley; 2009.

72. Haddaway N, Macura B, Whaley P, Pullin A. ROSES flow diagram for systematic reviews. Version 1.0. 2018.

73. Laurel BJ, Gregory RS, Brown JA. Settlement and distribution of age-0 juvenile cod, Gadus morhua and G. ogac, following a large-scale habitat manipulation. Mar Ecol Prog Ser. 2003;262:241-52.

74. Reed DC, Schroeter SC, Huang D, Anderson TW, Ambrose RF. Quantitative assessment of different artificial reef designs in mitigating losses to kelp forest fishes. Bull Mar Sci. 2006;78:133-50.

75. Reed DC, Schroeter SC, Page M: Annual Report of the Status of Condition C. Kelp reef mitigation in 2016. San Onofre Nuclear Generating station (SONGS) mitigation program. 2017. p. 71.

76. Levings ECD, Nishimura DJH. Created and restored sedge marshes in the lower Fraser River and estuary: an evaluation of their functioning as fish habitat. Can Tech Rep Fish Aquat Sci. 1996;2126:143-143. 
77. Stoklosar Scott A. Influence of constructed shoreline and islands on nearshore fish community structure in Hamilton Harbour, Ontario. MSC Thesis, Trent University, Peterborough, Canada. 1997.

78. Hansen JP, Snickars M. Applying macrophyte community indicators to assess anthropogenic pressures on shallow soft bottoms. Hydrobiologia. 2014;738:171-89.

79. Sandström MA, Karås SP. Tests of artificial substrata as nursery habitat for young fish. J Appl Ichthyol. 2002;18:102-5.

80. Pondella II, Daniel J, Stephens JS Jr. Factors affecting the abundance of juvenile fish species on a temperate artificial reef. Bull Mar Sci. 1994;55:1216-23.

81. Reese MM, Stunz GW, Bushon AM. Recruitment of estuarine-dependent nekton through a new tidal inlet: the opening of Packery Channel in Corpus Christi, TX, USA. Estuaries Coasts. 2008:31:1143-57.

82. Jessee WN, Carpenter AL, Carter JW. Distribution patterns and density estimates of fishes on a southern California artificial reef with comparisons to natural kelp-reef habitats. Bull Mar Sci. 1985:37:214-26.

83. Koricheva J, Gurevitch J, Mengersen K. Handbook of meta-analysis in ecology and evolution. Princeton: Princeton University Press; 2013

84. Bushman B, Wang MC. Vote-counting procedures in meta-analysis. In: Cooper $\mathrm{H}$, Hedges LV, Valentine JC, editors. The handbook of research synthesis and meta-analysis. New York: Russell Sage Foundation; 2009 p. 207-20.

85. Toft JD, Cordell JR, Simenstad CA, Stamatiou LA. Fish distribution, abundance, and behavior at nearshore habitats along city of Seattle marine shorelines, with an emphasis on juvenile salmonids. Seattle Public Utilities 2004. p. 52.

86. Scyphers SB, Powers SP, Heck KL, Byron D. Oyster reefs as natural breakwaters mitigate shoreline loss and facilitate fisheries. PLOS ONE. 2011;6(8):12.

87. Gristina M, Cardone F, Desiderato A, Mucciolo S, Lazic T, Corriero G. Habitat use in juvenile and adult life stages of the sedentary fish Hippocampus guttulatus. Hydrobiologia. 2017;784(1):9-19.

88. Sargent PS, Gregory RS, Schneider DC. Density responses of subarctic coastal marine fish and crabs to artificial reefs. Trans Am Fish Soc. 2006:135:348-60.

89. Matthews KR. a comparative study of habitat use by young-of-the-year, subadult, and adult rockfishes on four habitat types in central Puget Sound. Fish Bull. 1990;88:223-39.

90. Tallman Jessica C, Forrester Graham E. Oyster grow-out cages function as artificial reefs for temperate fishes. Trans Am Fish Soc. 2007;136:790-9.

91. Pastor J, Koeck B, Astruch P, Lenfant P. Coastal man-made habitats: potential nurseries for an exploited fish species, Diplodus sargus (Linnaeus, 1758). Fish Res. 2013;148:74-80.

92. Galst CJ, Anderson TW. Fish-habitat associations and the role of disturbance in surfgrass beds. Mar Ecol Prog Ser. 2008;365:177-86.

93. Levin PS. Habitat structure, conspecific presence and spatial variation in the recruitment of a temperate reef fish. Oecologia. 1993;94:176-85.

94. O'Connor KC, Anderson TW. Consequences of habitat disturbance and recovery to recruitment and the abundance of kelp forest fishes. J Exp Mar Biol Ecol. 2010;386:1-10.

95. Harwell HD, Posey MH, Alphin TD. Landscape aspects of oyster reefs: effects of fragmentation on habitat utilization. J Exp Mar Biol Ecol. 2011:409:30-41.

96. Jenkins GP, Keough MJ, Hamer PA. The contributions of habitat structure and larval supply to broad-scale recruitment variability in a temperate zone, seagrass-associated fish. J Exp Mar Biol Ecol. 1998;226:259-78.

97. Able KW, Hagan SM, Brown SA. Mechanisms of marsh habitat alteration due to Phragmites: response of young-of-the-year mummichog (Fundulus heteroclitus) to treatment for Phragmites removal. Estuaries. 2003;26(2):484-94.

98. David AT, Ellings CS, Woo I, Simenstad CA, Takekawa JY, Turner KL, Smith AL, Takekawa JE. Foraging and growth potential of juvenile chinook salmon after tidal restoration of a large river delta. Trans Am Fish Soc. 2014;143(6):1515-29.

99. Houde ED. Emerging from Hjort's shadow. Northw Atl Fish Sci. 2008:41:53-70.
100. Abdel-Fattah S, Hasnain S. What are the impacts on temperate fish productivity of shoreline works activities? A systematic review protocol. Environ Evid. 2017:6:31.

101. Bulmer R, Kelly S, Jeffs A. Hanging basket oyster farming: assessing effects on seagrass using aerial photography. Aquac Environ Interact. 2012;2:285-92.

102. Eriander L, Laas K, Bergström P, Gipperth L, Moksnes PO. The effects of small-scale coastal development on the eelgrass (Zostera marina L.) distribution along the Swedish west coast. Ecological impact and legal challenges. Ocean Coast Manag. 2017;148:182-94.

103. Silliman BR, Bertness MD. Society for conservation biology shoreline development drives invasion of Phragmites australis and the loss of plant diversity on New England salt marshes. Conserv Biol. 2004:15:1424-34.

104. Deza AA, Anderson TW. Habitat fragmentation, patch size, and the recruitment and abundance of kelp forest fishes. Mar Ecol Prog Ser. 2010;416:229-40.

105. Jenkins GP, Wheatley MJ. The influence of habitat structure on nearshore fish assemblages in a southern Australian embayment: comparison of shallow seagrass, reef-algal and unvegetated sand habitats, with emphasis on their importance to recruitment. J Exp Mar Biol Ecol. 1998;221:147-72.

106. Pihl L, Baden S, Kautsky N, Rönnbäck P, Söderqvist T, Troell M, Wennhage $H$. Shift in fish assemblage structure due to loss of seagrass Zostera marina habitats in Sweden. Estuar Coast Shelf Sci. 2006:67:123-32.

107. Mayer-Pinto M, Ignacio BL, Széchy MTM, Viana MS, Curbelo-Fernandez MP, Lavrado HP, Silva SHG. How much is too little to detect impacts? A case study of a nuclear power plant. PLoS ONE. 2012;7:1-9.

108. Wiens JA. Spatial scaling in ecology. Funct Ecol. 1989;3:385-97.

109. Tournois J, Darnaude AM, Ferraton F, Aliaume C, Mercier L, McKenzie DJ. Lagoon nurseries make a major contribution to adult populations of a highly prized coastal fish. Limnol Oceanogr. 2017;62:1219-33.

110. Verdiell-Cubedo D, Oliva-Paterna FJ, Ruiz-Navarro A, Torralva M. Assessing the nursery role for marine fish species in a hypersaline coastal lagoon (Mar Menor, Mediterranean Sea). Mar Biol Res. 2013;9:739-48.

111. Woodland RJ, Secor DH, Fabrizio MC, Wilberg MJ. Comparing the nursery role of inner continental shelf and estuarine habitats for temperate marine fishes. Estuar Coast Shelf Sci. 2012:99:61-73.

112. Courrat A, Lobry J, Nicolas D, Laffargue P, Amara R, Lepage M, Le Pape O. Anthropogenic disturbance on nursery function of estuarine areas for marine species. Estuar Coast Shelf Sci. 2009;81:179-90.

113. Cheminée A, Pastor J, Bianchimani O, Thiriet P, Sala E, Cottalorda J-M, Francour $P$. Juvenile fish assemblages in temperate rocky reefs are shaped by the presence of macro-algae canopy and its three-dimensional structure. Sci Rep. 2017;7:14638.

114. Leslie T, James NC, Potts WM, Rajkaran A. The relationship between habitat complexity and nursery provision for an estuarine-dependent fish species in a permanently open South African Estuary. Estuar Coast Shelf Sci. 2017:198:183-92.

115. Dafforn KA, Glasby TM, Airoldi L, Rivero NK, Mayer-Pinto M, Johnston EL. Marine urbanization: an ecological framework for designing multifunctional artificial structures. Front Ecol Environ. 2015;13:82-90.

116. Brown E, Vasconcelos $R$, Wennhage H, Bergström U, Støttrup J Wolfshaar van de K, Millisenda G, Colloca F, Le Pape O. Conflicts in the coastal zone: human impacts on commercially important fish species utilizing coastal habitat. ICES J Mar Sci. 2018:fs×237.

117. Chambers RC, Trippel EA. Early life history and recruitment in fish populations. London: Chapman and Hall; 1997.

118. Schmitt R, Holbrook S. Mortality of juvenile damselfish: implications for assessing processes that determine abundance. Ecology. 1999;80:35-50.

119. Bjornstad O, Fromentin J-M, Stenseth N, Gjosaeter J. A new test for density-dependent survival: the case of coastal cod populations. Ecology. 1999;80:1278-88.

120. Hilborn R, Quinn TP, Schindler DE, Rogers DE. Biocomplexity and fisheries sustainability. Proc Natl Acad Sci. 2003:100:6564-8.

121. Miller J, Burke J, Fitzhugh G. Early life history patterns of Atlantic North American flatfish: likely and (unlikely) factors controlling recruitment. Neth J Sea Res. 1991;27:261-75.

122. Beverton R. Spatial limitation of population size: the concentration hypothesis. Neth J Sea Res. 1995;34:1-6. 